\title{
A New Extended MILP MRP Approach to Production Planning and Its Application in the Jewelry Industry
}

\author{
Erhan Yazıcı, ${ }^{1}$ Gülçin Büyüközkan, ${ }^{2}$ and Murat Baskak ${ }^{1}$ \\ ${ }^{1}$ Industrial Engineering Department, Istanbul Technical University, Istanbul, Turkey \\ ${ }^{2}$ Industrial Engineering Department, Galatasaray University, Istanbul, Turkey \\ Correspondence should be addressed to Erhan Yazıc1; erhan.yazici@technoroma.com
}

Received 8 October 2015; Accepted 18 January 2016

Academic Editor: Anna M. Gil-Lafuente

Copyright (C) 2016 Erhan Yazıc1 et al. This is an open access article distributed under the Creative Commons Attribution License, which permits unrestricted use, distribution, and reproduction in any medium, provided the original work is properly cited.

\begin{abstract}
It is important to manage reverse material flows such as recycling, reusing, and remanufacturing in a production environment. This paper addresses a production planning problem which involves reusing of scrap and recycling of waste that occur in the various stages of the production process and remanufacturing/recycling of returns in a closed-loop supply chain environment. An extended material requirement planning (MRP) is proposed as a mixed integer linear programming (MILP) model which includes-beside forward-these reverse material flows. The proposed model is developed for the jewelry industry in Turkey, which uses gold as the primary resource of production. The aim is to manage these reverse material flows as a part of production planning to utilize resources. Considering the mostly unpredictable nature of reverse material flows, the proposed model is likewise transformed into a fuzzy model to provide a better review of production plan for the decision maker. The suggested model is examined through a case study to test the applicability and efficiency.
\end{abstract}

\section{Introduction}

In terms of production planning, MRP has a key role which generates outputs such as production orders, capacity requirements, and raw and semimaterial requirements by using customer orders, bill of materials (BOM), routings for capacity requirements as main data, and inventory status records as initial planning status $[1,2]$. Classical MRP only considers forward material flows. Many papers that include details about the MRP process can be found in the literature. In addition to classical MRP process, there is also another type that handles reverse material flows which is called reverse MRP [3] that takes into account the disassembly of the products as a separate process alone. Additionally, another approach takes both forward and reverse movements into consideration together at production planning which extends MRP approach that is proposed by Grubbström [4] using Laplace transformation for manufacturing and remanufacturing of product at the same time. Grubbström's approach was extended within production recycling in addition to finished product's recycling by Kovačić and Bogataj [5].
The jewelry industry has a distinctive characteristic due to its use of precious metals as raw materials. Using metals as a raw material is a specific characteristic needed to be analyzed in the view of production planning as precious metals are recyclable and reusable in production. Using precious metals such as gold also has its financial value. Considering the customer and supplier-based material movements, jewelry production can be considered as a closed-loop supply chain. The extended MRP approach is capable of giving a basic solution to the production planning problem of jewelry industry. But it needs to be expanded and extended to consider the specific production characteristics of jewelry.

The existing research on extended MRP approach which is proposed Grubbström [4] and improved by Kovačić and Bogataj [5] uses an input-output model by using matrices to solve the MRP process by basically using only BOM and predefined ratios, periodicity being excluded. The cost is not taken into the consideration for reusing or recycling decisions and there is no cost minimization for recycling, supplying, or reusing decisions. There should be a time interval of the scraps collected for economic recycling level. Scrap and loss 
ratios of production are not so deterministic and have to be managed as an uncertainty. Furthermore, there should be a decision mechanism to remanufacture or recycle a returned product. A financial deduction is registered as gold on the side of the supplier, as gold is used as a currency in financial reports. Besides, there is a periodicity in production and capacity constraints. These are the motivations of this paper to resolve for the jewelry sector of Turkey. It is anticipated that this paper may open new perspectives for other researchers, other industries, and countries seeking guidance for dealing with their similar problems. When the literature is reviewed, there is no similar research for this type of problem. Moreover, it is not probable to obtain MRP approach for jewelry.

The main objective of this paper is to reach a solution for jewelry production planning problem in Turkey. The production process involves back and forth movements simultaneously. Gold is used as a raw material and financial instrument at the same time. Collections and returns of gold from customers, its purchasing, and its recycling from suppliers and everything in production activities relate to material movements of gold and have effects on production planning. Cost coefficients are used as ratios of production amount in the unit of gold. These are requirements which seem specific to the Turkish jewelry industry. A mathematical model has been proposed to resolve these problems, which has been observed to be nonlinear due to the description of some production processes. Nonlinear mathematical problems are hard to solve and there is no global optimal solution. Thus, using a linearization technique, this problem is defined as a mixed integer linear programming (MILP) mathematical model, which is solved to find an optimal solution. In summary, this example is transformed with fuzzy coefficients for reverse material flows such as recycling, which is difficult to forecast and includes uncertainty. This uncertainty is discussed in a number of papers on fuzzy MRP, especially by Mula et al. [6-11]. They used fuzzy methods to manage uncertainty in MRP for mathematical modelling. Particularly, Serna et al. proposed using parametric linear programming for production planning [12] and for protecting the linearity in order to obtain an optimal solution. Their approach is applied to the proposed extended MRP model in this paper to get a more reliable decision on production planning by handling uncertainties. Thus, the proposed model is transformed into a fuzzy extended MRP model.

The rest of the paper is arranged as follows. Relevant literature about MRP with recycling and remanufacturing and MRP including fuzzy solutions is reviewed in Section 2. In Section 3, the jewelry production and the proposed new extended MRP MILP model for the production planning problem are presented. Then, the proposed model is transformed with a fuzzy approach which is first described in general and then in particular for the recycling process in Section 4. In Section 5, the proposed deterministic and fuzzy models are solved for a real example in the jewelry industry. Finally, concluding remarks and directions for further research are provided in Section 6.

\section{Literature Review}

Currently, there are a bunch of studies about production planning and MRP in the literature. The literature was surveyed by considering the characteristics of the problem, production planning with recycling, reusing, and remanufacturing. The concept of fuzzy production planning is also reviewed due to handling uncertainty of recycling in production planning.

2.1. Production Planning with Recycling and Remanufacturing. There are various researches on production planning and MRP in the literature. There are also studies proposing mathematical models for MRP. Regarding cost minimization in a capacity and resource constrained environment, some authors reported mathematical programming models for MRP $[6,13]$. Billington et al. [13] proposed general mathematical modelling for MRP and presented an extensive review. Mula et al. [6] modified this model and presented a deterministic MRP model for optimization of production planning. Besides general MRP concept, recycling and remanufacturing in production planning issues are also reviewed in the literature.

There have been a number of literature surveys on remanufacturing and production planning. Junior and Filho [14] published a literature review about production planning and control for remanufacturing. They tried to define the complexity of remanufacturing and gave a perspective to researchers on that issue. Morgan and Gagnon [15] also reported a well-classified literature survey about remanufacturing scheduling. They suggested that reverse MRP can be a solution for the problem related to infinite capacity and single product remanufacturing scheduling problem. Lately, MRP models tend to seek solutions using cost-based integer programming models. Omar and Yeo [16] proposed a model for inventory system that considered both production and repair of products with time varying demand and multiple setups. They modelled new items and used items' production and repair runs at each time interval. Li et al. [17] studied the dynamic lot sizing problem with product returns and remanufacturing. They suggested an algorithm to fulfill customer demand for products and minimize the cost at a planning period by considering demand and returns for manufacturing and remanufacturing decisions. Kim et al. [18] developed a hybrid model to coordinate manufacturing and remanufacturing and effective disposal of new products. They made use of a Markov decision process to investigate the optimal policy. DePuy et al. [19] introduced a production planning method including remanufacturing. They described an MRP approach by discussing a case study, which included probabilities about returns and remanufacturing times. Corominas et al. [20] generated a joint aggregate planning of a system for manufacturing and remanufacturing. First, they proposed a nonlinear mathematical model with some breakdown function definitions and then used a piecewise linearization to transform it into a linear model. Wei et al. [21] considered an inventory and production planning problem about remanufacturing of returns at uncertain demand and in a finite planning horizon. Robust optimization approach 
with a robust linear programming model was employed to handle the uncertainty of demand and yields.

According to Guide Jr. et al. [22], recycling is a more valuable operation than remanufacturing and requires a more complex approach than traditional manufacturing. They aimed to define different and more complex structures in a literature survey and pointed out future perspectives for researchers interested in that issue. Additionally, they suggested that there was no MRP research about material recycling and recycle ratio uncertainty. Waste management and Green MRP are another way of recycling at production phase. Melnyk et al. [23] offered a Green MRP approach considering waste management within production planning and applied this approach on the American automotive industry. Mirzapour Al-e-hashem et al. [24] built up a stochastic programming model for multipoint, multiproduct, multiplant production planning problem in case of uncertain demand. They included waste management in their model and used numeric techniques for the linearization of nonlinear breakdown functions. Modelling of reverse material flows such as recycling, reusing, and remanufacturing in production planning generally ends up with nonlinear mathematical models due to processes that involve "if-then-else" structures. Corominas et al. [20] also used a piecewise linearization technique to convert nonlinear models into linear.

When MRP literature with recycling and remanufacturing processed is reviewed, reverse MRP and extended MRP approaches are observed. Grubbström [4] and Kovačić and Bogataj [5] and Barba-Gutiérrez et al. [3, 25] have published several studies on these issues. Kovačić and Bogataj [5] proposed an "input-output" model for material requirement planning, considering both the finished product and work in process materials recycling. This publication is based on Grubbström's [4] work which included just the recycling of the finished product. Barba-Gutiérrez and Adenso-Díaz [3] reviewed the MRP concept in reverse logistics.

Jewelry production is mostly done as make to order production, due to its use of valuable raw materials, such as gold, which is a frequent bottleneck in jewelry production. During the production planning process, gold always should be at the core, turning the production planning of jewelry into a gold-centric production planning. Everything about gold is important with all its details. When the literature is analyzed, no paper on this kind of production planning is observed, neither for jewelry nor for any similar industry. As an outlier, Süer et al. [26] have a few works about the production, including cases of jewelry, however not as an MRP issue. As a similar industry, aluminum manufacturing, which uses recyclable materials is discussed in a study by David et al. [27]. They demonstrated the benefits of enterprise resource planning (ERP) and MRP systems' usefulness in aluminum conversion industry.

Including customer and supplier-based material movements in the production planning process, jewelry production is considered as a closed-loop supply chain production, as it controls material movements of gold in every stage. Inderfurth et al. [28] reported a research about product recovery systems in a closed-loop supply chain, presented them in production planning, and demonstrated on a case study. Another extensive study by He [29] offered a closedloop supply chain model with recycling, reusing, and remanufacturing decisions for cost minimization.

Despite all these researches in related areas, there is not any research on MRP with recycling and remanufacturing in the literature. Particularly for jewelry industry, the MRP model is not researched by including aspects like recycling, remanufacturing, supplying, collecting, and returns. In this paper, recycling and remanufacturing are studied in a mathematical model for MRP and returned products and work in process materials is considered as recycle resource. Additionally, remanufacturing and recycling decision is included in the proposed model.

2.2. Production Planning and Fuzziness. In spite of deterministic characteristic of most studies, there are many uncertainties in real cases as a part of production planning process. Dealing with problems that contain uncertainties, fuzzy sets, and fuzzy logic, as proposed by Zadeh [30], is of great importance for researchers. Fuzzy approaches are more suited for resolving complex problems with uncertainty by defining human choices and thoughts on problems. The proposed model is therefore transformed into a fuzzy model to provide a better view of production planning for the decision maker. This transformation is carried out to deal with the mostly unpredictable nature of reverse material flows such as recycling, reusing, and remanufacturing.

Literature review papers about production planning and uncertainty are as follows: Guiffrida and Nagi [31] provided a survey of the application of the fuzzy set theory in production management research. This review consisted of 73 journal articles and nine books and classified fuzzy applications in production management research. Mula et al. [7] reviewed the literature about production planning under uncertainty and proposed a deterministic MRP for the optimization of production planning. Dolgui and Prodhon [32] constructed a detailed literature review on supply planning under uncertainties in an MRP environment.

In that respect, there are various studies about MRP with uncertainties. Fuzzy MRP problems are mostly examined by Mula et al. [9-11] and Mula et al. [6-11]. Mula et al. [6] proposed a fuzzy mathematical programming model for production planning under uncertainty. This model includes fuzzy constraints and fuzzy coefficients. Grabot et al. [33] suggested a guidance to explicitly model the uncertainty and imprecision of the demand, allowing to pass through all the MRP steps. Mula et al. [9] provided a new linear programming model for medium term production planning in a capacity constrained MRP. This included a multiproduct, multilevel, and multiperiod manufacturing environment with three fuzzy models with flexibility in the objective function, in the market demand, and in the available capacity of resources. Figueroa-García et al. [34] presented a general model of a mixed production planning problem with fuzzy demand. Fuzzy linear programming model (soft constraint model) has been used with an interval fuzzy set approach to define uncertainty. Peidro et al. [10] tried to prove the efficiency of a fuzzy mathematical programming approach 
to model a supply chain production planning problem with uncertainty in demand. Additionally, there are fuzzy production planning problems which occur in a supply chain. For example, Bilgen [35] presented a solution approach using fuzzy operators for production allocation and distribution problems in a supply chain network. Lu et al. [36] proposed a novel fuzzy multiobjective mixed integer linear programming model to multiproduct multistage integrated production planning problem. Weighted average method and fuzzy ranking method are used for defuzzification of fuzzy constraints at first phase. Then, an interactive resolution method is used with satisfaction degree of objectives considering decision makers' preference.

In addition to traditional production planning, some authors used a fuzzy approach with reverse movement. Pishvaee and Torabi [37] proposed a biobjective possibilistic mixed integer programming which integrates the network design decisions in both forward and reverse supply chain networks. An interactive fuzzy solution approach, which was basically a resolution method, was developed to solve problems interactively with the decision maker. Barba-Gutiérrez et al. [25] presented an MRP algorithm for scheduling the disassembly of discrete parts characterized by a well-defined product structure in an uncertain environment using reverse material requirements. Olugu and Wong [38] studied a fuzzyrule based performance evaluation system for closed-loop supply chain, which consisted of reverse movements.

Adding fuzzy constrains or coefficients to mathematical models generally makes models nonlinear. Mostly, $\alpha$-cuts fuzzy parametric linear programming approach is utilized to keep mathematical model linear, considering the difficulty of solving nonlinear mathematical problems. Those papers that use $\alpha$-cuts are as follows: Serna et al. [12] aimed at providing a materials requirement planning (MRP) problem with uncertainty in the automotive industry. They solved the problem by using fuzzy parametric linear programming. Parra et al. [39] proposed a method for solving multiobjective possibilistic problems through a fuzzy compromise programming approach. Their solution concept was founded on soft preference and indifference relationships and on the canonical representation of fuzzy numbers by means of $\alpha$-cuts. Beside linear mathematical modelling solutions, some papers used algorithms to solve the fuzzy production planning problem. Li et al. [17] showed a fuzzy programming model with recourse based on credibility theory which includes fuzzy variable coefficients related to the market demand and the unit cost of the fabric. They designed a hybrid algorithm which combines an approximation approach (AA) and particle swarm optimization (PSO). Lan et al. [40] studied a class of multiperiod production planning and sourcing problem with credibility service levels and designed an algorithm which is a combination of approximation approach, PSO, and neural networks. Srivastava and Nema [41] proposed a fuzzy parametric programming model for a multiobjective recycling problem under uncertainty. Zhang et al. [42] also formulated a generalized production planning problem under uncertainty with fuzzy intervals using $\alpha$-cuts fuzzy parametric linear programming and possibility degrees of decision makers. Chen and Huang [43] and Madadi and
Wong [44] used $\alpha$-cuts fuzzy parametric linear programming on aggregate production planning problem.

On that point there are also other papers handling uncertainties with linear results. Torabi et al. [45] dealt with a hierarchical production planning and scheduling problem which contains uncertainties and used an effective method to define fuzzy objective function. They made use of the weighted average method for defuzzification; then the problem is solved as linear model. Peidro et al. [10] proposed a fuzzy mathematical programming model for supply chain planning which considers supply, demand, and process uncertainties. The model was formulated as a fuzzy mixed integer linear programming model where data are illknown and modelled by triangular fuzzy numbers. Kundu et al. [46] proposed a new parametric linear programming method for type- 2 fuzzy intervals at different $\alpha$-cuts levels to solve fixed charge transportation problem. Srinivasan and Geetharamani [47] used $\alpha$-cuts levels with degree of satisfaction of the constraints where resources and technology coefficients are defined as type-2 fuzzy intervals. Yager [48] used a ranking function and $\alpha$-cuts to solve problems keeping them in linear form. Klir and Yuan [49] and Kacprzyk and Orlovski [50] proposed $\alpha$-cuts and an acceptance level-based soft constraints approach as a framework to solve problems which contain fuzzy parameters. Tanaka et al. [51] also used parametric solutions for fuzzy linear models. Liang [52] and Liang and Cheng [53] used a weighted average method for defuzzification to solve a fuzzy MOLP problem. Wang and Liang [54] also introduced a weighted average method.

In this paper, the presented extended MRP approach is transformed with fuzzy coefficients into a fuzzy extended MRP approach. This paper extends the literature by proposing a new approach for extended MRP on a jewelry case from Turkey which includes recycling, reusing, and remanufacturing decisions as a part of production planning processes. Additionally, due to the unpredictable nature of these reverse material movements, the proposed approach is also transformed into the fuzzy MRP application to handle uncertainties over this kind of process in production planning, contributing to the literature.

\section{Problem Description and Formulation}

This research's main motivation is the production planning problem encountered by a gold jewelry company in Turkey, which has to manage recycling, reusing, and remanufacturing in coordination with the production process. This cost minimization production planning problem contains multiple products, multiple plants, and capacity constraints of more than one period production environment, regarding only one bottleneck raw material, gold, and recycling, reusing, and remanufacturing of raw material gold and products containing gold as raw material. The problem involves material flows both for in process and out of process such as supply, demand, return, and collection of gold.

Jewelry production can be considered as a closed-loop supply chain production as material movements are both customer- and supplier-based so that material movements of 


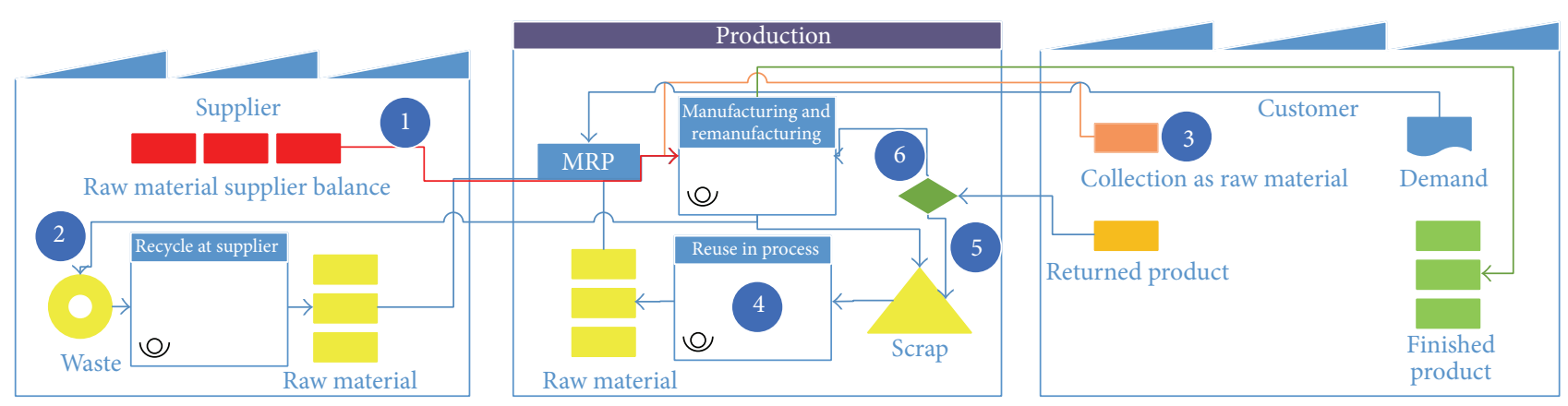

Raw material as gold

Raw material as gold used from supplier as liability

Returned product made by gold from customer

Collection as raw material gold from customer

Finished product made by gold at customer
Scrap gold in process reusable (physical recycle process needed for reuse)

Waste gold sent to supplier for recycle (chemical recycle process needed for reuse)

FIGURE 1: Jewelry production environment and material flows.

gold can be controlled in every stage of production planning. The problem's details and assumptions are given below for this jewelry closed-loop supply chain.

\section{In Production Related}

(i) Each product can be manufactured in different plants. Capacity is needed in different plants to produce the defined products. If capacity is not available in a plant, a penalty cost is determined.

(ii) All cost estimates are computed as the production of grams of gold. Gold itself is not regarded as a cost of production despite its raw material situation.

(iii) Only gold alone is considered as a raw material in the planning due to the bottleneck situation. Other raw materials like alloys and zircon stones are not considered as a part of planning as they are managed with safety stocks. If required, they can be easily appended to the model.

(iv) Scrap and waste come from the raw material (gold) flow used during the production.

(v) Scrap is collected from the production as reusable pieces. Waste occurs in the production process as granulated from and gathered with special methods.

(vi) Scrap is reused by collecting pieces physically and then just melting and reusing again in production.

(vii) Waste recycling consists of collection of gold dust with special filters from the air, water, and surfaces, applying a chemical process obtained from a specialist supplier and recycling as pure gold, which incurs a recycling cost.

(viii) The economic recovery amount of the accumulated waste for recycling is required.

(ix) Scrap reusing is limited and can be reprocessed in a certain cycle time due to its effects on the end product quality. At the end of this reusing cycle time, scrap must be committed to recycling. It is rather difficult to separate that portion of the gold used in output. Gold resource planners follow up with the scraps collected from production units and send them for recycling according to the quality of gold. After a sufficient period of time, it is assumed that the "used gold" is sent to recycling by considering the parameter reusable period.

\section{Supplier Concerned}

(i) Gold supply from suppliers is restricted with the debit balance limit, since gold is a valuable material which at the same time can be used as a financial instrument. This presents a balance risk when it is given to the customer as debit.

(ii) The chemical recycling process is performed by the supplier as it requires specialization, economic size, and a high initial investment.

\section{Customer Related}

(i) Production is made by demand of customers.

(ii) There is a cost for the backlogged demand in production planning duration. Backlogged demand is not desirable at the end of the planning horizon.

(iii) Returns from customers are decided to be sent for recycling or remanufacturing.

(iv) Payments are collected from customers as raw material gold. That is an interesting feature of the Turkish jewelry industry, which needs to be considered as part of the production planning.

All the above provided details of jewelry production are illustrated in Figure 1, showing production, recycling, reusing, and remanufacturing processes, together with material flows.

Descriptions of the icons are presented in the legend of Figure 1. In summary, the material flows, especially those that are numbered are explained as follows:

(i) Number 1 indicates the supply of gold from the vendor as pure gold. 
(ii) Number 2 represents recycle of waste which includes gold.

(iii) Number 3 displays collection from customers as gold.

(iv) Number 4 refers to the reuse of scrap gold, which occurs in production.

(v) Numbers 5 and 6 are about returned product's reuse, recycle, or remanufacturing decision. Number 6 stands for the decision of remanufacturing and number 5 shows the reusing decision.

In the next section, the problem is formulated with mathematical modelling.

3.1. Problem Formulation. For this production planning problem, a MILP MRP model is developed for the gold jewelry industry in Turkey with recycling, reusing, and remanufacturing. The proposed model considers reverse material flows both in processes, such as recycling, reusing, and remanufacturing, and out of processes, such as supplierbased recycling, returns, and collections from customers as raw material gold.

Main outputs of the proposed model are the main production schedule consisting of the products to produce and raw material needed; product and raw material stock quantity end of every period; amount of demand met; capacity usages; recycle, scrap, and waste quantities or raw material; returned product recycling and remanufacturing quantities; and the raw material supply amount for each period.

The main aims of the model are minimizing the total production cost; planning of scrap and waste recycling; planning return remanufacturing and recycling; planning of raw material supply (mainly gold supply in this model); minimizing demand backlog; minimizing finished product and raw material stock level; effective resources usage; considering scrap, waste and return recycling and collections as raw material gold to minimize supply cost and considering returned product remanufacturing to minimize total production cost.

Constraints of the model are the stock, production, and demand balance constraints for the finished product; raw material stock and supply constraints; operational resource capacity constraints and nonnegativity, binary, and integer subjections for the decision variables.

The proposed MILP model's sets, decision variables, cost coefficients as parameters, and needed initial data definitions used to formulate are described as follows.

\subsubsection{Notation}

Sets

$T$ : set of planning periods $(t=1,2, \ldots, T)$.

$I$ : set of raw materials $(i=1)(I=1$ is gold as raw material).

$P$ : set of products $(p=1,2, \ldots, P)$.

$J$ : set of production resources/plants $(j=1,2, \ldots, J)$.

\section{Parameters}

$\mathrm{cp}_{p}$ : variable cost of production of a unit of the product " $p$."

$\mathrm{cr}_{p}$ : variable cost of reprocess of a unit of the product "p."

$\mathrm{cc}_{p}$ : variable cost of recycle of a unit of the product "p."

$\mathrm{ci}_{p}$ : inventory cost of a unit of the product " $p$. ."

$\operatorname{crr}_{i}$ : recycle cost of a unit of the raw material " $i$."

$\mathrm{cru}_{i}$ : reuse cost of a unit of the raw material " $i$."

$\mathrm{crl}_{i}$ : recycle-lost cost of a unit of the raw material " $i$."

$\mathrm{cobl}_{i}$ : over balance cost of suppliers for the raw material " $i$."

$\mathrm{cdb}_{p, "}$ : backlogged demand cost of a unit of the product cuc $_{j}$ : unused capacity unit cost of the resource " $j$." $\operatorname{coc}_{j}$ : overtime capacity unit cost of the resource " $j$." $d_{p t}$ : market demand of the product " $p$ " in period " $t$." $g_{i p}$ : required quantity of the raw material " $i$ " to produce a unit of the product " $p$ ", $i=1$ as gold so it can be notated as $g_{p}$.

$y_{i p}$ : recyclable quantity waste of the raw material " $i$ " comes from production of a unit of the product " $p$."

$s_{i p}$ : reusable quantity scrap of the raw material " $i$ " comes from production of a unit of the product " $p$." $\mathrm{Pt}_{p}$ : required production period of the product " $p$." $\mathrm{Rcl}_{i}$ : recyclable quantity limit of the raw material " $i$." Rup $_{i}$ : reuse period of the raw material “ $i$."

$\mathrm{Bls}_{i}$ : supplier balance limit of the raw material " $i$."

$\mathrm{Rp}_{\text {pt }}$ : returned quantity of the product “ $p$ ” in period "t."

$\mathrm{Col}_{i t}$ : collected quantity of the raw material " $i$ " in period " $t$."

$\mathrm{Pc}_{p j}$ : required capacity unit of the resource " $j$ ” for unit of production of the product " $p$."

$\mathrm{Pcu}_{p j}$ : required capacity unit of the resource " $j$ " for unit of reprocess of the product " $p$."

$\operatorname{Rac}_{j t}$ : available capacity unit of the resource " $j$ " in period " $t$."

Data

Inv $_{p 0}$ : inventory of the product " $p$ " in period 0.

$\operatorname{Inv}_{i 0}$ : inventory of the raw material " $i$ " in period 0 .

$\operatorname{Rcyp}_{i 0}$ : recyclable inventory of the raw material “ $i$ " in period 0 .

$\operatorname{Reuc}_{i 0}$ : reusable inventory of the raw material " $i$ " in period 0 .

$\mathrm{Bd}_{p 0}$ : backlogged demand of the product " $p$ " in period 0 . 
$\mathrm{Bs}_{i 0}$ : supplier balance of the raw material " $i$ " in period " $t . "$

M: sufficiently high number, used for linearization.

\section{Decision Variables}

$\operatorname{Prd}_{p t}$ : quantity to production of the product " $p$ " in period " $t$."

Inv $_{p t}$ : inventory of the product " $p$ " at the end of period " $t$."

$\operatorname{Inv}_{i t}$ : inventory of the raw material " $i$ " at the end of period " $t$."

$\mathrm{Bd}_{p t}$ : demand backlog of the product " $p$ " at the end of period " $t$."

$\mathrm{Ucr}_{j t}$ : unused capacity of the resource " $j$ " in period " $t . "$

$\mathrm{Ocr}_{j t}$ : overtime capacity of the resource " $j$ " in period " $t$."

$\mathrm{Sm}_{i t}$ : supply quantity of the raw material “ $i$ " in period "t."

$\mathrm{Ruc}_{i t}$ : reused and recycled quantity of the raw material " $i$ " in period " $t$."

$\mathrm{Rcy}_{i t}$ : recycle quantity of the raw material " $i$ " in period " $t$."

$\operatorname{Reu}_{i t}:$ reuse quantity of the raw material " $i$ " in period "t."

Reuc $_{i t}$ : in reusing cycle, total quantity of the raw material " $i$ " in period " $t$."
$\mathrm{Rcyp}_{i t}$ : in pending recycle, total quantity of the raw material " $i$ " in period " $t$."

$\mathrm{Bs}_{i t}$ : balance of suppliers for the raw material " $i$ " in period " $t$."

Bols $_{i t}$ : over balance limit of suppliers for the raw material " $i$ " in period " $t$."

$\operatorname{Rprt}_{p t}$ : quantity to remanufacture of the returned product " $p$ " in period " $t$."

$\mathrm{Rcrt}_{p t}$ : quantity to send reusing process of the returned product " $p$ " in period " $t$."

$\mathrm{Rt}_{p t}$ : quantity returned of the product " $p$ " at the end of period " $t$."

$\operatorname{Prd}_{p j t}:$ quantity to manufacture of the product " $p$ " in period " $t$ " on resource “ $j$."

$\mathrm{Rprt}_{p j t}$ : quantity to remanufacture of the returned product " $p$ " in period " $t$ " on resource " $j$."

$\mathrm{Pr}_{i t}$ : recycle process existence ( 1 or 0 ) of the raw material " $i$ " in period " $t$," used for linearization.

$\mathrm{Po}_{i t}$ : over balance limit of supply existence ( 1 or 0 ) of the raw material " $i$ " in period " $t$," used for linearization.

$\mathrm{Pu}_{j t}$ : undercapacity use existence ( 1 or 0 ) of the resource " $j$ " in period " $t$," used for linearization.

Due to " $I$ " being defined only for gold as raw material, it can be used for all notations without " $i$ " indices. The model is especially defined with " $i$ " indices to be extensible for future researches in similar industries which need to handle more than one recyclable material.

3.1.2. Objective Function. Consider

Minimize

$$
\begin{aligned}
& \sum_{p=1}^{P} \sum_{t=1}^{T}\left(\mathrm{cp}_{u} \operatorname{Prd}_{p t}+\mathrm{ci}_{u} \operatorname{Inv}_{p t}+\mathrm{cdb}_{u} \mathrm{Bd}_{p t}\right) * g_{p} \\
& +\sum_{j=1}^{J} \sum_{t=1}^{T}\left(\mathrm{cuc}_{j} \mathrm{Ucr}_{j t}+\operatorname{coc}_{j} \mathrm{Ocr}_{j t}\right) \\
& +\sum_{i=1}^{I} \sum_{t=1}^{T}\left(\left(\operatorname{crr}_{i}+\mathrm{crl}_{i}\right) * \mathrm{Rcy}_{i t}+\mathrm{cru}_{i} \operatorname{Reu}_{i, t-\mathrm{Rup}_{i}-1}\right) \\
& +\sum_{p=1}^{P} \sum_{t=1}^{T}\left(\mathrm{cc}_{p} \mathrm{Rcrt}_{p t}+\mathrm{cr}_{p} \mathrm{Rprt}_{p t}+\mathrm{ci}_{p} \mathrm{Rt}_{p t}\right) * g_{p} \\
& +\sum_{i=1}^{I} \sum_{t=1}^{T} \operatorname{cobl}_{i} \mathrm{Bols}_{i t} .
\end{aligned}
$$

Equation (1) defines the total production cost to be minimized and contains 5 different terms. Term (1a) and term (1b) represent the order, production, inventory, and resource usage cost. In addition, when the supply of raw materials, recycling, and remanufacturing costs is added to the model, reverse movements will be integrated to it, as desired. Term 
(1c) shows the recycling and reusing cost of the raw material. Term (1d) shows the return, recycling, and remanufacturing cost of products. Term (1e) represents the supply cost and enforces balance between supply and reusing, recycling, and remanufacturing taking into account supply cost. Term (1a) and term (1d) contain a product by $g_{p}$ because, as mentioned before, all cost coefficients are used as ratios of production amount in gold units. In term (1a), term (1d), and term (1e), the decision variables are already determined as the amount of gold.

The objective is the minimization of the total of these costs. In addition to production, inventory, and capacity utilization, the costs of recycling, reusing, lost and remanufacturing costs, and raw material procurement costs are included. Constraints associated with the proposed model are described as follows, respectively.

\subsubsection{Model Constraints}

Inventory, Production, and Demand Balance Constraints for Product. Consider

$$
\begin{aligned}
& \operatorname{Inv}_{p t} \\
& =\operatorname{Inv}_{p, t-1}+\operatorname{Prd}_{p, t-\mathrm{Pt}_{p}}-d_{p t}-\mathrm{Bd}_{p, t-1}+\mathrm{Bd}_{p t} \\
& \quad+\operatorname{Rprt}_{p t} \quad \forall p, t, \\
& \mathrm{Rt}_{p t}=\mathrm{Rt}_{p, t-1}+\mathrm{Rp}_{p t}-\mathrm{Rcrt}_{p t}-\mathrm{Rprt}_{p t} \quad \forall p, t, \\
& \sum_{p=1}^{P}\left(\sum_{t=1}^{T}\left(\operatorname{Prd}_{p, t-\mathrm{Pt}_{p}}+\mathrm{Rprt}_{p t}\right)-\sum_{t=1}^{T} d_{p t}\right)=0 .
\end{aligned}
$$

Equation (2) corresponds to the inventory balance for products. The inventory of product at the end of the period planning horizon will be equal to the sum of stock from the previous period, existing period production, backlogged demand for the next period, and remanufacturing of existing period, where the previously backlogged demand and the demand of the existing period are to be subtracted. Equation (3) manages product return's recycling, reusing, and remanufacturing operations of products. It bears on the decision of returning product recycling, keeping in stock, or remanufacturing decisions. Equation (4) establishes the demand and production balance.

Inventory Balance Constraints for Raw Materials. Consider

$$
\begin{aligned}
\operatorname{Inv}_{i t}= & \operatorname{Inv}_{i, t-1}+\operatorname{Sm}_{i t}+\operatorname{Ruc}_{i t} \\
& -\sum_{p=1}^{P}\left(g_{i p}+y_{i p}+s_{i p}\right) \operatorname{Prd}_{p t}-\operatorname{Reuc}_{i, t-1}
\end{aligned}
$$

$\forall i, t$

$$
\mathrm{Ruc}_{i t}=\left(1-\frac{\mathrm{crl}_{i}}{1000}\right) * \mathrm{Rcy}_{i t}+\mathrm{Reuc}_{i t} \quad \forall i, t
$$

$$
\begin{aligned}
\operatorname{Reu}_{i t} & =\sum_{p=1}^{U} s_{i p} \operatorname{Prd}_{p t} \quad \forall i, t, \\
\operatorname{Reuc}_{i t} & =\operatorname{Reuc}_{i, t-1}+\operatorname{Reu}_{i t}-\operatorname{Reu}_{i, t-\operatorname{Rup}_{h}-1} \quad \forall i, t, \\
\operatorname{Rcyp}_{i t} & =\sum_{p=1}^{P} y_{i p} \operatorname{Prd}_{p t}+\operatorname{Rcyp}_{i, t-1}-\operatorname{Rcy}_{i t} \quad \forall i, t, \\
\operatorname{Rcy}_{i t} & = \begin{cases}\operatorname{Rcyp}_{i, t-1}, & \operatorname{Rcyp}_{i, t-1} \geq \operatorname{Rcl}_{i} \\
0, & \operatorname{Rcyp}_{i, t-1}<\operatorname{Rcl}_{i}\end{cases}
\end{aligned}
$$

$\forall i, t$.

Inventory balance constraints for raw materials include the supply, reusing, and recycling costs. Equation (5) shows the inventory balance for raw materials. Equations (6)-(10) show the recycling process. Recycling constraint Equation (6) Ruc ${ }_{i t}$ can directly be substituted into (5). Equation (7) collects the reusable quantity of production. With (8), reusing process is managed by regarding the reuse period limit. Equation (9) represents the accumulated amount of gold for the recycling process. $\mathrm{Rcy}_{i t}$ in (10) enforces the economically recyclable quantity to accumulate. If it reaches the amount defined as $\mathrm{Rcl}_{i}$, it can be sent to recycling. Here, by definition, $\mathrm{Rcy}_{i t}$ includes a nonlinear expression. In order to convert (10) from nonlinear to linear, the linearization of $\mathrm{Rcy}_{i t}$ is carried out as follows:

$$
\begin{aligned}
\operatorname{Rcl}_{i}-\mathrm{Rcyp}_{i, t-1} & \leq M *\left(1-\operatorname{Pr}_{i t}\right) \quad \forall i, t, \\
\operatorname{Rcyp}_{i, t-1}-\mathrm{Rcl}_{i} & \leq M * \operatorname{Pr}_{i t} \quad \forall i, t, \\
\operatorname{Rcyp}_{i, t-1}-\mathrm{Rcy}_{i t} & \leq M *\left(1-\operatorname{Pr}_{i t}\right) \quad \forall i, t, \\
\operatorname{Rcy}_{i t} & \leq M * \operatorname{Pr}_{i t} \quad \forall i, t, \\
\operatorname{Rcy}_{i t} & \leq \operatorname{Rcyp}_{i, t-1} \quad \forall i, t .
\end{aligned}
$$

When $\mathrm{Rcy}_{i t}$, the recyclable waste amount, approaches $\mathrm{Rcl}_{i}$, the economic recyclable quantity limit, and recycling can be performed. $\operatorname{Pr}_{i t}$ represents the existence of a recycling process that should be managed. Equation (11) controls the recycling process with economic size. The first two terms represent the existence of the recycling procedure because of the accumulated amount that reached the economic recycling limit, $\mathrm{Rcl}_{i}$. The third term ensures that the existing collected waste amount is reset once the recycling operations are completed. The fourth term enforces the recyclable amount to zero when it does not reach the economic size. Eventually, the last term guarantees that the recycling amount is equal to the accumulated amount, with coordination of the second condition.

Supply Balance Constraints of Raw Material. Consider

$$
\begin{aligned}
\mathrm{Bs}_{i t}= & \mathrm{Bs}_{i, t-1}-\mathrm{Reu}_{i, t-\mathrm{Rup}_{i-1}}-\sum_{p=1}^{P}\left(\mathrm{Rcrt}_{p t} * g_{i p}\right) \\
& -\mathrm{Col}_{i t}+\mathrm{Sm}_{i t} \quad \forall i, t,
\end{aligned}
$$




$$
\begin{aligned}
\mathrm{Bs}_{i t} & \leq \mathrm{Bls}_{i} \quad \forall i, t, \\
\mathrm{Bols}_{i t} & = \begin{cases}\mathrm{Bs}_{i t}-\mathrm{Bs}_{i, t-1}, & \mathrm{Bs}_{i t}-\mathrm{Bs}_{i, t-1}>0 \\
0, & \mathrm{Bs}_{i t}-\mathrm{Bs}_{i, t-1} \leq 0\end{cases}
\end{aligned}
$$

$$
\forall i, t \text {. }
$$

Equations (12)-(14) show supply balance constraints for raw materials. Equation (11) defines the supply balance and the $\operatorname{Reu}_{i, t-\mathrm{Rup}_{i-1}}$ variable is added as representing raw material should be sent to supplier after Rup $_{i}$ period reused for recycling and/or as a payment to the supplier. Thus, it decreases the balance of the supplier. The Rcrt $p t$ variable also represents the recycled returned products to raw material. The $\mathrm{Col}_{i t}$ variable represents the raw material "gold" that is collected as payment from customers, increasing its existing inventory. Hence, there will be no need of debit from supplier. Equation (13) restricts the supplier balance limit to $\mathrm{Bls}_{i}$.

Equation (14) shows the increase of debit balance of gold at the supplier. Increasing of debit means the use of supplier's gold. At that point, there should be a price for that. Besides, this is specified in the objective function in (1)'s term (1e). Here, by definition, Bols $s_{i t}$ includes a nonlinear expression. In order to convert (14) from nonlinear to linear, linearization equations of Bols $s_{i t}$ are presented as follows:

$$
\begin{aligned}
& \mathrm{Bs}_{i t}-\mathrm{Bs}_{I, t-1} \leq M * \mathrm{Po}_{i t} \quad \forall I, t, \\
& \mathrm{Bs}_{i, t-1}-\mathrm{Bs}_{i t} \leq M *\left(1-\mathrm{Po}_{i t}\right) \quad \forall i, t \\
& \mathrm{Bs}_{i, t-1}-\mathrm{Bs}_{i t}+\mathrm{Bols}_{i t} \leq M *\left(1-\mathrm{Po}_{i t}\right) \quad \forall i, t \\
& \mathrm{Bols}_{i t} \leq M * \mathrm{Po}_{i t} \quad \forall i, t, \\
& \mathrm{Bols}_{i t} \geq \mathrm{Bs}_{i, t-1}-\mathrm{Bs}_{i t} \quad \forall i, t .
\end{aligned}
$$

If there is not any increase in $\mathrm{Bs}_{i t}-\mathrm{Bs}_{i, t-1}$ on the debit balance of gold at the supplier side, there should be no difference in the first term. The second term guarantees the vice versa situation of the first term. The third term calculates the increase amount, Bols $s_{i t}$, at debit balance with coordination of last term. The fourth term ensures that it is zero if there is no increase in the balance.

Resource Capacity Constraints for Plants. Consider

$$
\begin{aligned}
& \sum_{p=1}^{P}\left(\operatorname{Pc}_{p j} \operatorname{Prd}_{p j t}+\operatorname{Pcu}_{p j} \operatorname{Rprt}_{p j t}\right)-\operatorname{Ocr}_{j t}+\mathrm{Ucr}_{j t} \\
& \quad=\operatorname{Rac}_{j t} \quad \forall j, t, \\
& \sum_{j=1}^{J} \sum_{p=1}^{P} \operatorname{Prd}_{p j t}=\operatorname{Prd}_{p t} \quad \forall p, t,
\end{aligned}
$$

$$
\begin{aligned}
& \sum_{j=1}^{J} \sum_{p=1}^{P} \mathrm{Rprt}_{p j t}=\operatorname{Rprt}_{p t} \quad \forall p, t, \\
& \operatorname{Ocr}_{j t}= \begin{cases}\operatorname{Ocr}_{j t}, & \mathrm{Ucr}_{j t}=0 \\
0, & \mathrm{Ucr}_{j t}>0\end{cases}
\end{aligned}
$$

$$
\mathrm{Ucr}_{j t}= \begin{cases}\mathrm{Ucr}_{j t}, & \mathrm{Ocr}_{j t}=0 \\ 0, & \mathrm{Ocr}_{j t}>0\end{cases}
$$

$$
\forall j, t .
$$

Equations (16)-(20) show the resource capacity balance for production plants. In addition to normal manufacturing times, remanufacturing times in (16) manage the capacity usage of plants. Equations (17) and (18) sum up all plants' manufacturing and remanufacturing amounts of products to the total production amount. Equations (19) and (20) identify the capacity usage of production plants, whether they are operating at over- or undercapacity. Here, by definition, $\mathrm{Ocr}_{j t}$ and $\mathrm{Ucr}_{j t}$ include a thought which is expressed in nonlinear form. In order to convert (19) and (20) from nonlinear to linear, the linearization equations of $\mathrm{Ocr}_{j t}$ and $\mathrm{Ucr}_{j t}$ used in (19) and (20) are formulated as follows:

$$
\begin{aligned}
& \operatorname{Ocr}_{j t} \leq M *\left(1-\mathrm{Pu}_{j t}\right) \quad \forall j, t, \\
& \mathrm{Ucr}_{j t} \leq M * \mathrm{Pu}_{j t} \quad \forall j, t .
\end{aligned}
$$

Both (19) and (20) are managed with one binary parameter, because whenever one of them exists, the other one will not.

\section{Nonnegativity, Binary, and Integer Constraints. Consider}

$$
\begin{aligned}
& \operatorname{Prd}_{p t}, \operatorname{Inv}_{p t}, \operatorname{Bd}_{p t}, \operatorname{Rprt}_{p t}, \operatorname{Rcrt}_{p t}, \operatorname{Prd}_{p j t}, \operatorname{Rprt}_{p j t}, \mathrm{Rt}_{p t}, \\
& \quad \mathrm{Ucr}_{j t}, \operatorname{Ocr}_{j t} \geq 0, \\
& \operatorname{Inv}_{i t}, \operatorname{Ruc}_{i t}, \operatorname{Rcy}_{i t}, \operatorname{Reu}_{i t}, \operatorname{Reuc}_{i t}, \operatorname{Rcyp}_{i t} \geq 0, \\
& \operatorname{Sm}_{i t}, \mathrm{Bs}_{i t}, \operatorname{Bols}_{i t} \geq 0, \\
& \operatorname{Bd}_{p T}=0, \\
& \operatorname{Prd}_{p t}, \operatorname{Inv}_{p t}, \operatorname{Bd}_{p t}, \operatorname{Rprt}_{p t}, \operatorname{Rcrt}_{p t}, \operatorname{Prd}_{p j t}, \operatorname{Rprt}_{p j t}, \mathrm{Rt}_{p t} \\
& \quad \in \mathrm{Z}, \\
& \operatorname{Pr}_{i t}, \operatorname{Po}_{i t}, \operatorname{Pu}_{j t} \in\{0,1\},
\end{aligned}
$$

$$
\forall i, j, p, t \text {. }
$$

Finally, (22) guarantees the nonnegativity, integer, and binary constraints of decision variables.

\section{Fuzzy Approach for Recycle Process}

In addition to the deterministic model which is presented in the preceding section, the proposed approach also transformed the model into a fuzzy MILP model for MRP to 
handle uncertainties, so that the unpredictable nature of reverse material movements like recycle process efficiency in production planning can be taken into account. The proposed deterministic model certainly defines all aspects of the problem. However, the effectiveness of the adopted recycling process in the proposed model is difficult to predict deterministically. Beside that uncertainty, also as our literature survey suggests, there exist other uncertainties based on demand, supply, process, and environment. The scope of this paper is limited to recycling uncertainty only, because of the high financial value of gold as the raw material in the jewelry industry. Although recycling is not a hundred percent efficient process, the amount of loss remains uncertain.

The proposed MILP approach is modeled nonlinearly by definition at first hand. Therefore, there is no optimal solution and the model is difficult to solve. To manage this challenge, binary linearization is used to transform it into a MILP model, meaning that adding fuzzy definitions to the model also will change model to nonlinear. To deal with this situation, the proposed MILP is transformed according to linear programming fuzzy solutions. As the fuzzy set approach to handle uncertainty, parametric linear programming is used with $\alpha$-cuts and an interactive resolution method with decision maker which is proposed by Jiménez et al. [55], Peidro et al. [10], and Mula et al. [6]. For the fuzzy interval approach, the parametric linear programming method proposed by Kundu et al. [46] is used.

4.1. Type-1 Fuzzy (Fuzzy Set) Approach. In the proposed MILP model, the recycling process efficiency is defined as uncertain according to (6) and also (1), because it is cost coefficient at the same time. $\mathrm{crl}_{i}$ is the recycle-lost cost of a unit of the raw material " $i$," only gold in this case. In the jewelry industry, unit cost measure is determined as a portion of gold weight. It is set as a percentage of recyclable gold collected as waste in production. $\mathrm{crl}_{i}$, the recycle-lost cost as ratio of gold weight, is used in the objective function as a cost coefficient and in a constraint to calculate recycled quantity. That is because of the nature of gold, which is both a raw material and a financial instrument at the same time. $\mathrm{crl}_{i}$ recycle-lost cost is presented as a triangular fuzzy number (TFN): $\widetilde{\operatorname{crl}}_{i}=\left(\mathrm{crl}_{i a}, \mathrm{crl}_{i b}, \mathrm{crl}_{i c}\right)$.

The membership function to describe a fuzzy set is proposed in Gen et al. [56]:

$$
\begin{aligned}
\mu_{\widetilde{c r l}_{i}}(x) & =\mu_{\widetilde{c r l}_{i}}\left(x: \mathrm{crl}_{i a}, \mathrm{crl}_{i b}, \mathrm{crl}_{i c}\right) \\
& = \begin{cases}\frac{x-\mathrm{crl}_{i a}}{\mathrm{crl}_{i b}-\mathrm{crl}_{i a}}, & \text { if } \mathrm{crl}_{i a} \leq x \leq \mathrm{crl}_{i b} \\
\frac{\mathrm{crl}_{i c}-x}{\operatorname{crl}_{i c}-\mathrm{crl}_{i b}}, & \text { if } \mathrm{crl}_{i b} \leq x \leq \mathrm{crl}_{i c} \\
0, & \text { if } x>\operatorname{crl}_{i c} \text { or } x<\operatorname{crl}_{i a} .\end{cases}
\end{aligned}
$$

The interactive resolution method used here contains $\alpha$-cuts which represents the acceptable feasibility degree of the fuzzy coefficient. $\alpha_{0}$ stands for the minimum coefficient feasibility degree that the decision maker is willing to accept. Then, the feasibility interval of $\alpha$ is $\alpha_{0} \leq \alpha \leq 1$. A discrete scale proposed by Jiménez et al. [55] is applied with 0.1 interval steps, which ranges from unacceptable to completely acceptable solution. Accordingly, the corresponding ordinary linear program for each $\alpha$ at intervals of 0.1 cuts are solved. The $\alpha$-parametric linear programming transformation of fuzzy model is carried out by applying the proposed method by Jiménez et al. $[10,55]$ with $(24)$ as an equivalent of (1) and (6) which consists of recycle-lost cost. Consider the following:

$$
\begin{aligned}
& \sum_{p=1}^{P} \sum_{t=1}^{T}\left(\mathrm{cp}_{p} \operatorname{Prd}_{p t}+\mathrm{ci}_{p} \mathrm{Inv}_{p t}+\mathrm{cdb}_{p} \mathrm{Bd}_{p t}\right) * g_{p}+\sum_{j=1}^{J} \sum_{t=1}^{T}\left(\mathrm{cuc}_{j t} \mathrm{Ucr}_{j t}+\mathrm{coc}_{j} \mathrm{Ocr}_{j t}\right) \\
& \quad+\sum_{i=1}^{I} \sum_{t=1}^{T}\left(\left(\mathrm{crr}_{i}+\left((1-\alpha) * \frac{\left(\mathrm{crl}_{i b}+\mathrm{crl}_{i c}\right)}{2}+\alpha * \frac{\left(\mathrm{crl}_{i a}+\mathrm{crl}_{i b}\right)}{2}\right)\right) * \mathrm{Rcy}_{i t}+\mathrm{cru}_{i} \mathrm{Reu}_{i, t-\mathrm{Rup}_{i-1}}\right) \\
& \quad+\sum_{p=1}^{P} \sum_{t=1}^{T}\left(\mathrm{cc}_{p} \operatorname{Rcrt}_{p t}+\mathrm{cr}_{p} \mathrm{Rprt}_{p t}+\mathrm{ci}_{p} \mathrm{Rt}_{p t}\right) * g_{p}+\sum_{i=1}^{I} \sum_{t=1}^{T} \operatorname{cobl}_{i} \mathrm{Bols}_{i t}, \\
& \widetilde{\mathrm{Ruc}_{i t}} \cong\left(1-\frac{\left((1-\alpha) *\left(\left(\mathrm{crl}_{i b}+\mathrm{crl}_{i c}\right) / 2\right)+\alpha *\left(\left(\operatorname{crl}_{i a}+\mathrm{crl}_{i b}\right) / 2\right)\right)}{1000}\right) * \mathrm{Rcy}_{i t}+\operatorname{Reuc}_{i t} \quad \forall i, t .
\end{aligned}
$$

After solving the $\alpha$-parametric linear programs for acceptable feasibility degrees of the fuzzy coefficient, the decision maker specifies satisfaction degrees of each solution of the parametric linear program with $\alpha$-cuts. Using these satisfaction degrees, the decision maker obtains an insight about different $\alpha$ acceptable feasibility degrees' impact on the total cost of production and will make his/her planning accordingly, regarding that uncertainty's effect on the production plan.
4.2. Type-2 Fuzzy (Fuzzy Interval) Approach. Using the fuzzy set approach, the uncertainty of the recycling process is assumed to only have one dimension to consider in the proposed model. This type of uncertainty is described as type-1 uncertainty. On the other hand, according to the size of uncertainty dimension more dimensions of uncertainty can be taken into account when examining it, called type- $n$ uncertainty by Zadeh $[57,58]$. For recycling process losses, 
uncertainty can vary by plants and different product groups in production planning term. If the decision maker wants to consider these situations together, then recycling losses can be defined as a type-2 $[57,58]$ uncertainty. In the preceding fuzzy set approach, recycling cost is defined as a triangular fuzzy number. However, in fuzzy interval approach, it is defined as a triangular fuzzy area.
The type-2 fuzzy interval of $\mathrm{crl}_{i}$ can be represented as $\widetilde{\operatorname{crl}}_{i}=\left(\operatorname{crl}_{i}^{1}, \operatorname{crl}_{i}^{2}, \operatorname{crl}_{i}^{3} ; \theta_{l, i}, \theta_{r, i}\right)$ type-2 TFN [46]. Here, $\mathrm{crl}_{i}^{1}, \mathrm{crl}_{i}^{2}$, and $\mathrm{crl}_{i}^{3}$ are real numbers and represent type-1 uncertainties. $\theta_{l, i}$ and $\theta_{r, i}$ show type- 2 triangular fuzzy area variables' type-1 uncertainty distribution intervals. At type2 level, the uncertainty distribution interval membership function defined as $\widetilde{\mu}_{\mathrm{crl}_{i}}(x)$ is given with (25) [46]. In all cases, memberships are given as type-1 fuzzy sets:

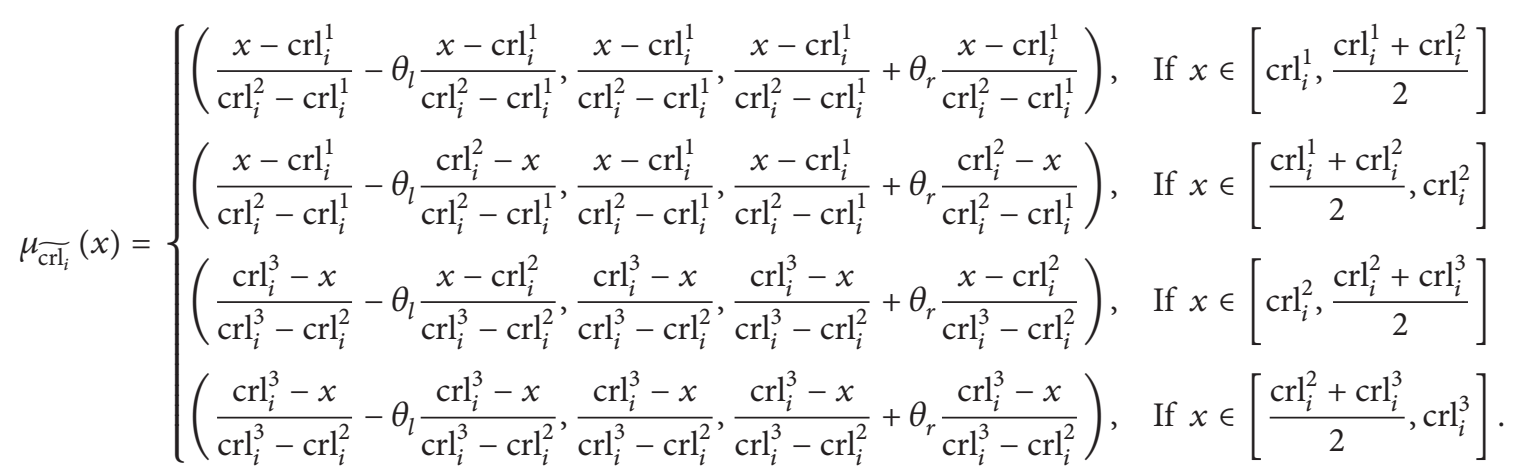

When applying the defuzzification method proposed by Kundu et al. [46] for different $\alpha$ value interval cases as presented in preceding membership function, the equivalent crisp parametric equations of (6) become the form presented below. Also for (1), the crisp equivalent parametric objective function can be rewritten using the same defuzzification method.

Case $1(0<\alpha \leq 0.25)$. Consider

$$
\begin{aligned}
& \widetilde{\operatorname{Ruc}_{i t}} \\
& \cong\left(1-\left(\frac{\left(1-2 \alpha+(1-4 \alpha) \theta_{r, i}\right) \mathrm{crl}_{i}^{1}+2 \propto \mathrm{crl}_{i}^{2}}{1+(1-4 \alpha) \theta_{r, i}}\right)\right) \\
& \quad * \operatorname{Rcy}_{i t}+\operatorname{Reuc}_{i t} \quad \forall i, t .
\end{aligned}
$$

Case $2(0.25<\alpha \leq 0.5)$. Consider

$$
\begin{aligned}
& \widetilde{\mathrm{Ruc}_{i t}} \\
& \cong\left(1-\left(\frac{(1-2 \alpha) \mathrm{crl}_{i}^{1}+\left(2 \alpha+(4 \alpha-1) \theta_{l, i}\right) \mathrm{crl}_{i}^{2}}{1+(4 \alpha-1) \theta_{l, i}}\right)\right) \\
& \quad * \operatorname{Rcy}_{i t}+\operatorname{Reuc}_{i t} \quad \forall i, t .
\end{aligned}
$$

Case $3(0.5<\alpha \leq 0.75)$. Consider

$$
\begin{aligned}
& \widetilde{\operatorname{Ruc}_{i t}} \cong(1 \\
& \left.\quad-\left(\frac{(2 \alpha-1) \mathrm{crl}_{i}^{3}+\left(2(1-\alpha)+(3-4 \alpha) \theta_{l, i}\right) \mathrm{crl}_{i}^{2}}{1+(3-4 \alpha) \theta_{l, i}}\right)\right) \\
& \quad * \operatorname{Rcy}_{i t}+\operatorname{Reuc}_{i t} \quad \forall i, t .
\end{aligned}
$$

Case $4(0.75<\alpha \leq 1)$. Consider

$$
\begin{aligned}
\widetilde{\mathrm{Ruc}_{i t}} & \cong(1 \\
& \left.-\left(\frac{\left(2 \alpha-1+(4 \alpha-3) \theta_{r, i}\right) \mathrm{crl}_{i}^{3}+2(1-\alpha) \mathrm{crl}_{i}^{2}}{1+(4 \alpha-3) \theta_{r, i}}\right)\right) \\
& * \operatorname{Rcy}_{i t}+\operatorname{Reuc}_{i t} \quad \forall i, t .
\end{aligned}
$$

The other constraints and coefficients still remain the same as the deterministic model. Then, the interactive resolution method is used to solve the problem for every acceptable feasibility degree of $\alpha$, using the related case's equations (1) and (6).

\section{Application to a Turkish Jewelry Company with a Case Study}

5.1. Background of the Case Company. The proposed model developed for the production planning problem is applied on one of Turkey's leading jewelry manufacturers, importers, and exporters which is called ABC Jewelry. The name is not disclosed to keep anonymity. ABC Jewelry Company is engaged in manufacturing fine gold jewelry products since 1992 and has 25 tons per year manufacturing capacity of fine gold in its facilities with 23,000 square meters closed area. ABC Jewelry Company exports nearly half of its production to 45 countries around the world, including USA and the European Union. The company also sells its products in the domestic market, supplying to about 2000 local jewelry retailers.

The company uses a production planning system which is based on standard MRP. The company takes orders from both domestic and foreign customers. Weekly production plans 


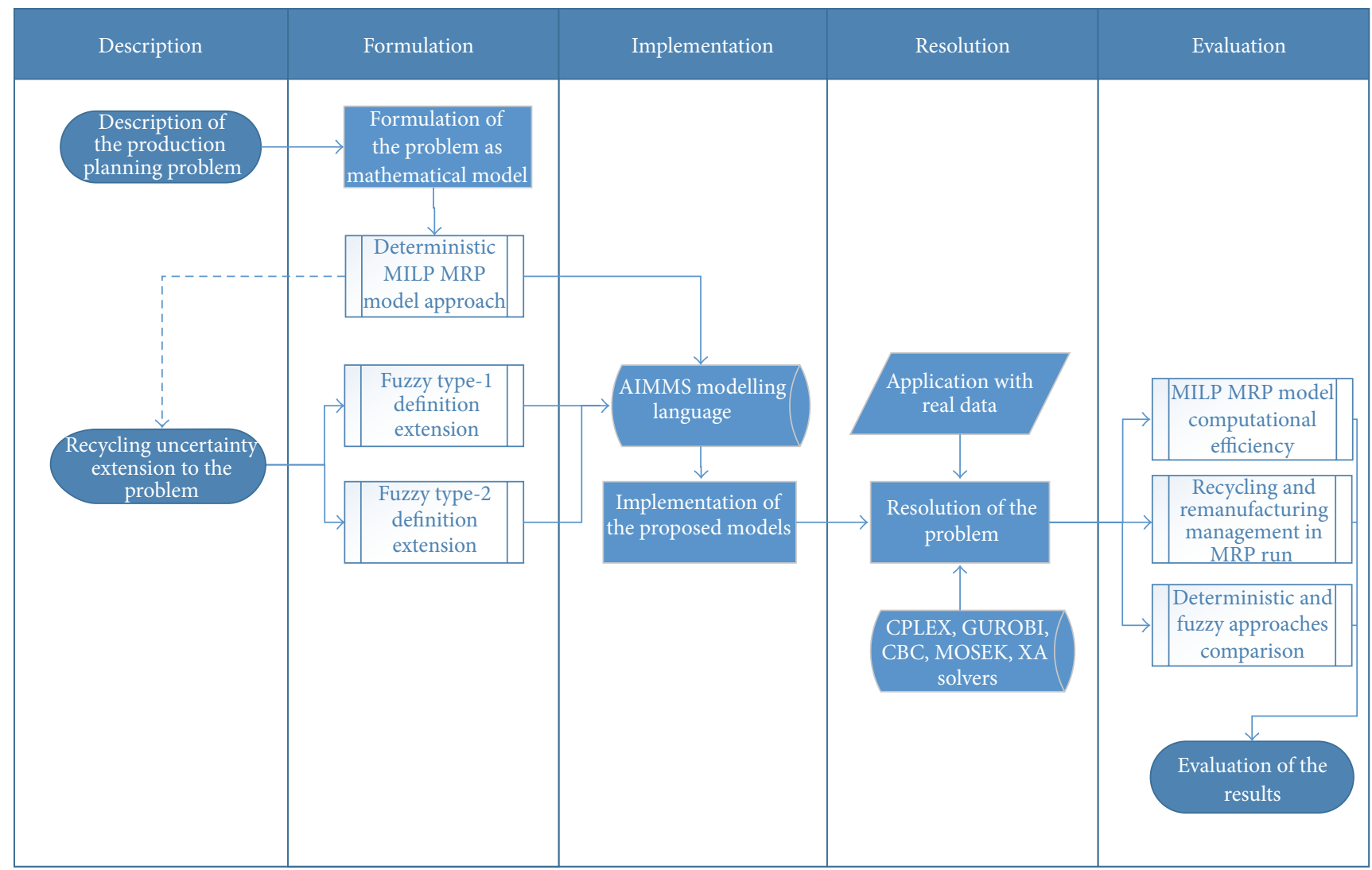

Figure 2: Flow chart of the problem resolution.

are made on a daily basis, by taking the deadlines of orders received into account. Orders are planned by considering the production cost and production capacity in the plants, since products can be produced in different plants. As the raw material, gold is the main bottleneck in planning and must be used in the most effective manner. In jewelry the planning of the raw material with all aspects is the basis of production planning. The purpose of this section is to demonstrate that the production planning can be carried out by considering recycling, reusing, and remanufacturing with the proposed model.

5.2. Implementation and Resolution. In addition to the given details and assumptions provided in the previous sections, specific issues to be considered in this case are as follows:

(i) There are 4 manufacturing plants.

(ii) Planning period is 2 weeks and production planning is done on a daily basis.

(iii) Manufacturing plants are operated 5 days per week during normal work hours. If there is a need for overcapacity, overtime is possible.

(iv) There exist 45 different products of 7 different product groups in the planning horizon. All are taken into account. (v) Suppliers of gold are considered as one supplier to manage balance in total.

(vi) It assumed that no work in production stock exists in that planning.

(vii) The data used in this study are obtained from the production planning software which is used by the case company, provided as an appendix (see Supplementary Material available online at http://dx .doi.org/10.1155/2016/7915673) to this paper.

(viii) The uncertainty of the recycling process is determined as TFN and TFV by decision makers, who are production managers.

Figure 2 illustrates the steps of the problem-solving process until the results of the problem are found. The MILP MRP model proposed in this paper was implemented using the modelling language AIMMS 4.1 x64 [59] and solved by the solvers CPLEX 12.5, CBC 2.7.5, GUROBI 5.5, MOSEK 6.0 , and XA 15 to evaluate model performance. The input data and models are managed on AIMMS 4.1 x64 [59] as different cases of deterministic and fuzzy problems. The computer environment used for evaluation has an Intel i52557M 1.70 GHz Dual Core Processor and 4 GB Ram running on Windows 7 x64. 
TABLE 1: Efficiency of application for different planning periods and solvers.

\begin{tabular}{|c|c|c|c|c|c|c|c|}
\hline Period (w) & Solver & Iteration & Constraint & Variable & Integer & Nonzero & CPU time (s) \\
\hline \multirow{5}{*}{2} & CPLEX 12.5 & 1,413 & \multirow{5}{*}{2,631} & \multirow{5}{*}{6,981} & \multirow{5}{*}{60} & \multirow{5}{*}{18,319} & 0.11 \\
\hline & СBC 2.7.5 & 518 & & & & & 0.64 \\
\hline & GUROBI 5.5 & 1,171 & & & & & 0.23 \\
\hline & MOSEK 6.0 & 5,115 & & & & & 0.70 \\
\hline & XA 15 & 1,016 & & & & & 0.19 \\
\hline \multirow{5}{*}{3} & CPLEX 12.5 & 2,808 & \multirow{5}{*}{3,901} & \multirow{5}{*}{10,471} & \multirow{5}{*}{90} & \multirow{5}{*}{27,729} & 0.28 \\
\hline & СВС 2.7.5 & 1,460 & & & & & 2.25 \\
\hline & GUROBI 5.5 & 4,488 & & & & & 0.42 \\
\hline & MOSEK 6.0 & 15,588 & & & & & 3.32 \\
\hline & XA 15 & 5,342 & & & & & 1.36 \\
\hline \multirow{5}{*}{4} & CPLEX 12.5 & 6,264 & \multirow{5}{*}{5,171} & \multirow{5}{*}{13,961} & \multirow{5}{*}{120} & \multirow{5}{*}{37,139} & 2.32 \\
\hline & СBC 2.7 .5 & 2,303 & & & & & 16.21 \\
\hline & GUROBI 5.5 & 16,701 & & & & & 3.74 \\
\hline & MOSEK 6.0 & 37,529 & & & & & 12.12 \\
\hline & XA 15 & $2,970,445$ & & & & & $2,933.65$ \\
\hline
\end{tabular}

5.3. Obtained Results with Deterministic Approach. As the initial step, the proposed deterministic MILP MRP model is taken into account. As the planning horizon, a two-week period is used primarily for planning. Because of the financial value of the gold, customers prefer to work with short-range order instead of long-term stock. The model performance is therefore also assessed for longer planning horizons with three and four-week period planning. The aim is to ensure the efficiency of the computational performance for the proposed model, independent from the planning horizon. Table 1 shows this computational efficiency of the proposed deterministic MILP MRP model. The data comprise the number of iterations, constraints, variables, integers and nonzero elements, and solving time of solvers.

Figure 3 presents the results for comparing the computational performance of the proposed model for increased planning period at different solvers using given CPU times at Table 1 .

The results indicate that all solvers are able to find a solution to the proposed deterministic MRP problem, as given in Table 1. CPLEX 12.5 and GUROBI 5.5 solvers are the best ones in terms of solving performance by solving time for the proposed model, as presented in Figure 3.

In addition to the computational efficiencies, the proposed MILP MRP model also provides insights on how recycling, reusing, and remanufacturing can be managed in the production planning. In Table 2 , the raw materialbased decision variables that are run for a four-week based production planning problem are presented. All values in Table 2 are calculated as a gram of gold with the indices " $I$ " and indices " $p$ " variables are given as pieces quantity. The production planning for a four-week period is applied to especially emphasize the reverse material flows.

The intent of presenting Table 2 is to demonstrate how recycling, reusing, and remanufacturing operations are covered in the proposed extended MILP MRP model. In the first

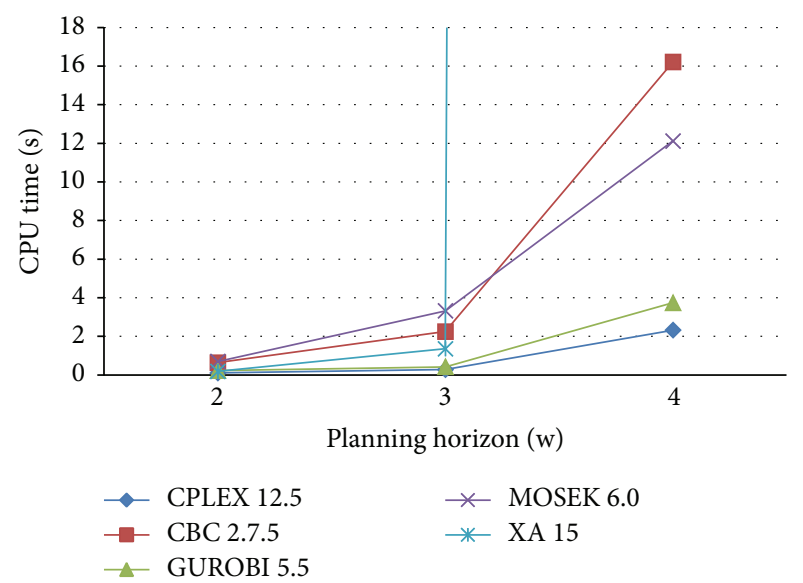

FIGURE 3: Difference of CPU times of solvers with respect to different planning horizons.

two columns, the planning period is given as weeks and days. Decision variable $\mathrm{Rcyp}_{i t}$ represents the accumulated quantity of recyclable raw material gold. The economic size of recycling is determined as 2000 grams of gold $\left(\mathrm{Rcl}_{i}=2000\right.$, see Supplementary Table Coefficients\&Init (RawMaterial)). So, at the end of day 4 , the accumulated gold in waste reaches this threshold and on day 5 the period planning shows a recycling process with $\mathrm{Pr}_{i t}$ and $\mathrm{Rcy}_{i t}$ decision variables. It also increases the variable $\mathrm{Ruc}_{i t}$, representing total of reused and recycled quantity and as seen at variable $\mathrm{Inv}_{i t}$ the model adds that value to stock of gold. Variables Reuc ${ }_{i t}$ and $\mathrm{Reu}_{i t}$ indicate the reusing process in coordination with the recycling process on variable $\mathrm{Ruc}_{i t}$. Periodically, enough period used gold is sent to the recycling process by regarding $\mathrm{Rup}_{i}$ which is reusable period. Here, an example is also given for the remanufacturing decision for returned products. At period 18, one 
TABLE 2: Production planning decision variables values for raw material (gold).

\begin{tabular}{|c|c|c|c|c|c|c|c|c|c|c|c|c|c|c|c|}
\hline \multicolumn{2}{|c|}{ Period } & \multirow{2}{*}{$\mathrm{Rcyp}_{i t}$} & \multirow{2}{*}{$\mathrm{Rcy}_{i t}$} & \multirow{2}{*}{$\mathrm{Ruc}_{i t}$} & \multirow{2}{*}{ Reuc $_{i t}$} & \multirow{2}{*}{$\operatorname{Reu}_{i t}$} & \multirow{2}{*}{$\operatorname{Inv}_{i t}$} & \multirow{2}{*}{$\mathrm{Sm}_{i t}$} & \multirow{2}{*}{$\mathrm{Col}_{i t}$} & \multirow{2}{*}{$\operatorname{Pr}_{i t}$} & \multirow{2}{*}{$\mathrm{Bs}_{i t}$} & \multirow{2}{*}{$\mathrm{Rp}_{p t}$} & \multirow{2}{*}{$\mathrm{Rprt}_{p t}$} & \multirow{2}{*}{$\mathrm{Rt}_{p t}$} & \multirow{2}{*}{$\mathrm{Rcrt}_{p t}$} \\
\hline & (d) & & & & & & & & & & & & & & \\
\hline 0 & 0 & 500 & & & 3,000 & 3,000 & 100,000 & & & & & & & & \\
\hline \multirow{5}{*}{1} & 1 & 792 & & 3,577 & 3,577 & 577 & 94,018 & & & & & & & & \\
\hline & 2 & 1,362 & & 4,572 & 4,572 & 995 & 84,948 & & & & & & & & \\
\hline & 3 & 1,788 & & 5,423 & 5,423 & 851 & 76,022 & & & & & & & & \\
\hline & 4 & 2,087 & & 3,021 & 3,021 & 598 & 69,748 & 3,000 & & & & & & & \\
\hline & 5 & 69 & 2,087 & 4,627 & 2,582 & 138 & 70,350 & 577 & & 1 & & & & & \\
\hline \multirow{5}{*}{2} & 6 & 100 & & 1,648 & 1,648 & 61 & 79,717 & 10,995 & 10,000 & & & & & & \\
\hline & 7 & 442 & & 1,451 & 1,451 & 655 & 73,137 & 851 & & & & & & & \\
\hline & 8 & 966 & & 1,790 & 1,790 & 936 & 64,371 & 598 & & & & & & & \\
\hline & 9 & 1,392 & & 2,502 & 2,502 & 850 & 55,445 & 138 & & & & & & & \\
\hline & 10 & 1,675 & & 3,005 & 3,005 & 563 & 49,551 & 61 & & & & & & & \\
\hline \multirow{5}{*}{3} & 11 & 1,689 & & 2,378 & 2,378 & 28 & 59,384 & 10,655 & 10,000 & & & & & & \\
\hline & 12 & 2,006 & & 2,075 & 2,075 & 634 & 54,863 & 936 & & & & & & & \\
\hline & 13 & 420 & 2,006 & 4,029 & 2,063 & 838 & 48,679 & 850 & & 1 & & & & & \\
\hline & 14 & 855 & & 2,360 & 2,360 & 861 & 39,743 & 563 & & & & & & & \\
\hline & 15 & 1,287 & & 3,071 & 3,071 & 738 & 33,177 & 28 & & & & & & & \\
\hline \multirow{5}{*}{4} & 16 & 1,684 & & 3,231 & 3,231 & 794 & 34,840 & 10,634 & 10,000 & & & & & & \\
\hline & 17 & 2,000 & & 3,016 & 3,016 & 624 & 28,389 & & & & & & & & \\
\hline & 18 & 2,000 & & 2,155 & 2,155 & & 28,389 & & & & & 35 & 35 & & \\
\hline & 19 & 2,000 & & 1,417 & 1,417 & & 28,389 & & & & & & & & \\
\hline & 20 & 2,000 & & 624 & 624 & & 28,389 & & & & & & & & \\
\hline
\end{tabular}

product with 35 pieces is returned by the customer and the returned products are forwarded to remanufacturing to meet the demand of that product, as presented with variable Rprt which stands for the remanufactured product quantity (see Supplementary Table Demand\&Return (Product)).

5.4. Resolution with Fuzzy Approaches. In the second step, uncertainty of the recycling process is considered in the proposed model. Recycling loss cost $\widetilde{\mathrm{crl}}_{i}$ is defined by the decision maker in the jewelry company as TFN $\widetilde{\operatorname{crl}}_{i}=(100,20,0)$ as a type-1 fuzzy set. It is defined as 20 in the deterministic model $\left(\mathrm{crl}_{i}=20\right.$; see Supplementary Table Coefficients\&Init (RawMaterial)). In Figure 4, the representation of recyclelost cost $\mathrm{crl}_{i}$ is shown as TFN. The feasibility degrees $\alpha$ of recycle process, which represent the values that the decision maker is willing to admit, are determined in set $M_{1}$, with $M_{1}=\{0.7,0.8,0.9,1\}$ for fuzzy type-1 solution by decision maker using solutions in Table 2.

As the consecutive step, the recycle-lost cost is reviewed as second order fuzzy dimension. It is determined by the decision maker in the jewelry company as type- 2 triangular fuzzy variable (TFV) with ${\widetilde{\mathrm{crl}_{i}}}_{i}=(100,20,0 ; 0.7,0.3)$. The feasibility degrees $\alpha$ of the recycling process, in which the decision maker is willing to admit, are the same as in the type-1 fuzzy problem. According to the acceptable feasibility degrees, case 3 needs to consider (28) and case 4 needs to consider (29) as parametric linear equations to solve. In Figure 5, the recycle-lost cost $\mathrm{crl}_{i}$ is depicted as the footprint

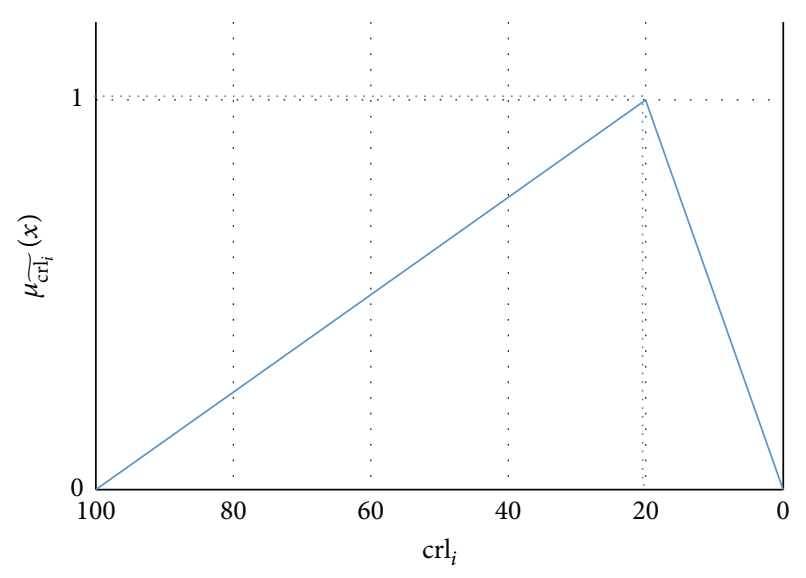

FIGURE 4: TFN presentation of recycle-lost cost $\mathrm{crl}_{i}$.

of uncertainty (FOU) by using the given uncertainty distribution interval membership function $\widetilde{\mu}_{\widetilde{c r l}_{i}}(x)$. The feasibility degrees $\alpha$ of the recycling process, in which the decision maker is willing to admit, are determined in set $M_{2}$, with $M_{2}=\{0.3,0.4,0.5,0.6,0.7,0.8\}$ for fuzzy type-2 solution by decision maker using solutions in Table 2.

In order to compare the impacts of the deterministic model and fuzzy approaches on the total cost of the recycling process, solutions obtained by all approaches are summarized as follows. The deterministic model is solved using deterministic data and fuzzy approaches also use the same data except 
TABLE 3: Total production cost for deterministic, fuzzy type-1, and fuzzy type-2 model solutions.

\begin{tabular}{|c|c|c|c|}
\hline Feasibility degree & Total cost (deterministic) & Total cost (fuzzy type-1) & Total cost (fuzzy type-2) \\
\hline 0 & & $1,569,539.96$ & $1,649,539.96$ \\
\hline 0.1 & & $1,559,539.96$ & $1,622,421.31$ \\
\hline 0.2 & & $1,549,539.96$ & $1,589,162.60$ \\
\hline 0.3 & & $1,539,539.96$ & $1,545,680.31$ \\
\hline 0.4 & & $1,529,539.96$ & $1,511,573.54$ \\
\hline 0.5 & & $1,519,285.69$ & $1,488,291.57$ \\
\hline 0.6 & & $1,508,954.32$ & $1,482,458.80$ \\
\hline 0.7 & & $1,498,622.94$ & $1,473,734.89$ \\
\hline 0.8 & & $1,488,291.57$ & $1,462,446.86$ \\
\hline 0.9 & & $1,477,924.93$ & $1,449,223.49$ \\
\hline 1 & & $1,467,540.91$ & $1,446,772.86$ \\
\hline Deterministic & $1,488,291.57$ & & \\
\hline
\end{tabular}

for the recycling process. For the recycling process, type-1 fuzzy approach is used with a TFN for defining uncertainty related to recycling lost cost. The type- 2 approach also uses the same TFN with an interval area which was given before in this section. The solution obtained by using $\alpha$ parametric equations and the solution method with acceptable feasibility degrees and satisfaction of different $\alpha$ cut solutions which are determined by the decision maker are explained in the preceding section.

5.5. Evaluation of the Obtained Results. In order to evaluate the efficiency of the model solution, the proposed model is run for periods longer than 2 weeks as well, such as 3 and 4 weeks. Nevertheless, the actual planning period in the case company is 2 weeks, as longer periods are not very realistic without many revisions. To identify the effect on the results and to compare with the deterministic solution, fuzzy models are run only for the 2 -week planning period. For this comparison, CPLEX 12.5 solver is used for all evaluations, because it is the most effective solver for the proposed deterministic model. Solver times are not provided for this comparison, since the solution for fuzzy models is already obtained with parametric linear equations, meaning that it is also deterministic and has almost the same CPU times. Fuzzy model solutions are found with CPLEX 12.5 solver. Table 3 summarizes the planned total production costs for the deterministic, fuzzy type-1, and fuzzy type- 2 model solutions.

Figure 6 presents the total production cost changes according to feasibility degrees $\alpha$ between deterministic and fuzzy model solutions. With this presentation, the decision maker gains valuable insight into the uncertainty of recycling processes' impact on total production costs, with which the most satisfactory solution can be selected. As seen in Figure 5, the deterministic cost is a crisp solution, so that the decision maker is not able to analyze the impact of recycling loss on production planning. Fuzzy type-1 model's parametric solution gives a better insight to decision makers. The resolution range for feasibility degree $\alpha$ provides a better point of view to the decision maker. Figure 5 also shows that the fuzzy type- 2 approach offers a better insight about uncertainty for the decision maker regarding the recycling

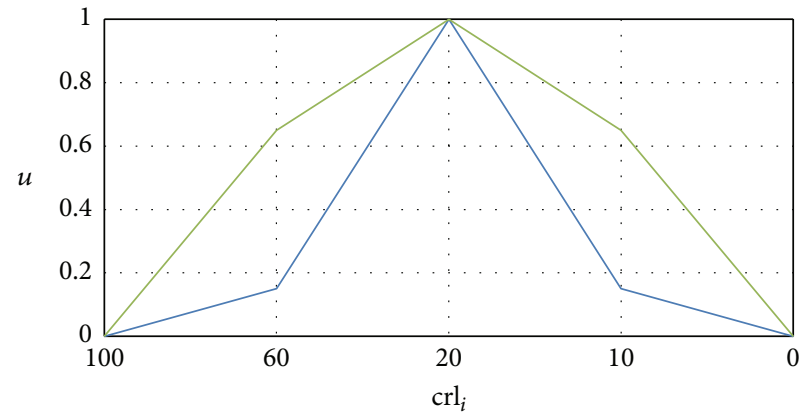

FIGURE 5: Type-2 triangular fuzzy interval presentation; FOU of recycle-lost cost $\mathrm{crl}_{i}$.

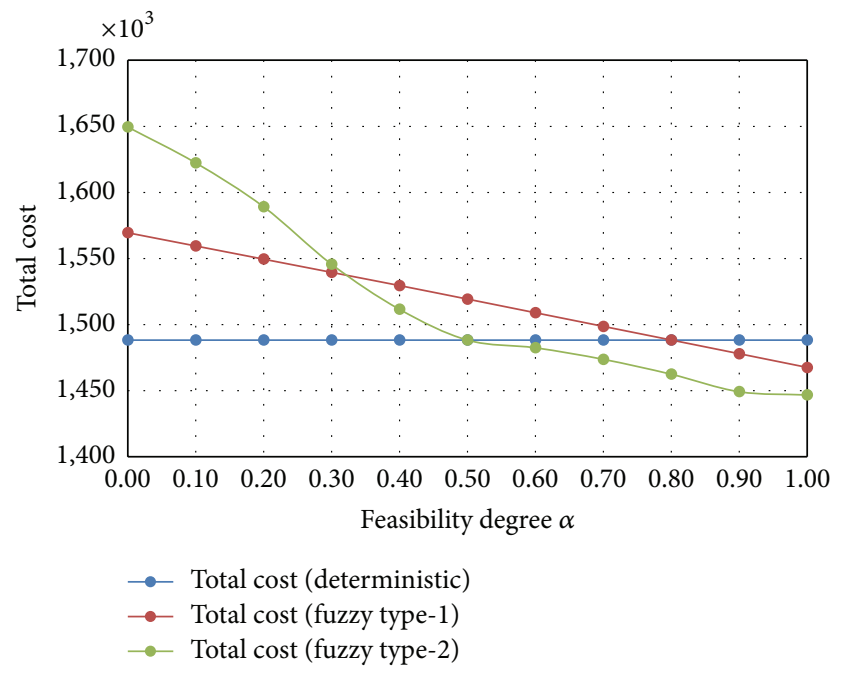

FIGURE 6: Total cost comparison of deterministic and fuzzy models by feasibility degree $\alpha$.

loss cost. It considers the spread of uncertainty around the deterministic solution more accurately. Consequently, the decision maker can select the most satisfactory feasibility degree $\alpha$ solution as a planning decision. 
The outcomes indicate that the proposed MILP MRP model satisfies the planning problem of jewelry production, which includes reverse material flows such as recycling, reusing and remanufacturing. The main aim of this production planning is to effectively manage gold inventory in coordination of manufacturing, reuse, recycle, and remanufacturing processes simultaneously, at the same time meeting other standard production planning requirements involving demand and capacity.

\section{Conclusion}

This paper proposes an extended material requirement planning (MRP) model using a mixed integer linear programming (MILP) technique for the production planning problem of jewelry industry in Turkey by regarding recycling, reusing, and remanufacturing in addition to standard production planning. The proposed model covers both forward and reverse material flows in a closed-loop jewelry supply chain which considers process, supply, and customer side simultaneously. Furthermore, linear fuzzy programming methods are applied taking the unpredictable nature of the recycling process into account with fuzzy type- 1 and type- 2 uncertainty. These are the main contributions of this paper which extend literature.

The proposed model and fuzzy applications are examined using data from ABC Jewelry Company. The computational performance of the proposed deterministic model is presented for different solvers and planning periods. The results for the production planning run indicate how the proposed model handles reverse material flows. Deterministic and fuzzy model solutions are compared in terms of total cost variations for different feasibility degrees. Projections of fuzzy approaches for decision makers are presented. It is demonstrated that the fuzzy approach gives a better perspective to decision makers. The main objective is the efficient utilization of gold, a challenge for production managers, where the model proposes a solution to this main bottleneck of production. This effective production planning approach mostly satisfies company shareholders and production planners. Application of the proposed model indicates that it is practical and usable both for achieving solutions in terms of computational effort and for effective production planning.

Finally, potential directions for further researches are pointed as below:

(i) Beside the main bottleneck, which is the raw material, consideration of all bills of materials should be helpful, as in the standard production planning.

(ii) Other raw materials which are also recyclable (i.e., precious stones and alloys for jewelry) can be considered to extend the model, with recyclable and nonrecyclable materials. Different recycle rules should also be set as needed.

(iii) All suppliers, customers, and plants can be defined separately in the model to manage closed-loop supply chain in particular. (iv) Use of different uncertainty handling approaches and fuzzy models can be helpful to reflect a better explanation of decision maker's experience about fuzzy variables.

(v) Definition of other uncertain variables can help produce a more realistic solution. As a guidance, in process, demand and supply-based variables can be considered.

(vi) The proposed model in this paper can be adapted to jewelry industries in other countries, or to similar industries that are using metals in production.

\section{Conflict of Interests}

The authors declare that there is no conflict of interests regarding the publication of this paper.

\section{References}

[1] D. N. P. Murthy and L. Ma, "MRP with uncertainty: a review and some extensions," International Journal of Production Economics, vol. 25, no. 1-3, pp. 51-64, 1991.

[2] G. Plenert, "Focusing material requirements planning (MRP) towards performance," European Journal of Operational Research, vol. 119, no. 1, pp. 91-99, 1999.

[3] Y. Barba-Gutiérrez and B. Adenso-Díaz, "Reverse MRP under uncertain and imprecise demand," International Journal of Advanced Manufacturing Technology, vol. 40, no. 3-4, pp. 413424, 2009.

[4] R. W. Grubbström, "Transform methodology applied to some inventory problems," Zeitschrift für Betriebswirtschaft, vol. 77, no. 3, pp. 297-324, 2007.

[5] D. Kovačić and L. Bogataj, "Multistage reverse logistics of assembly systems in extended MRP Theory consisting of all material flows," Central European Journal of Operations Research, vol. 19, no. 3, pp. 337-357, 2011.

[6] J. Mula, R. Poler, and J. P. Garcia, "MRP with flexible constraints: a fuzzy mathematical programming approach," Fuzzy Sets and Systems, vol. 157, no. 1, pp. 74-97, 2006.

[7] J. Mula, R. Poler, J. P. García-Sabater, and F. C. Lario, "Models for production planning under uncertainty: a review," International Journal of Production Economics, vol. 103, no. 1, pp. 271-285, 2006.

[8] J. Mula, R. Poler, and J. P. Garcia-Sabater, "Material requirement planning with fuzzy constraints and fuzzy coefficients," Fuzzy Sets and Systems, vol. 158, no. 7, pp. 783-793, 2007.

[9] J. Mula, D. Peidro, and R. Poler, "The effectiveness of a fuzzy mathematical programming approach for supply chain production planning with fuzzy demand," International Journal of Production Economics, vol. 128, no. 1, pp. 136-143, 2010.

[10] D. Peidro, J. Mula, M. Jiménez, and M. del Mar Botella, "A fuzzy linear programming based approach for tactical supply chain planning in an uncertainty environment," European Journal of Operational Research, vol. 205, no. 1, pp. 65-80, 2010.

[11] D. Peidro, J. Mula, R. Poler, and J.-L. Verdegay, "Fuzzy optimization for supply chain planning under supply, demand and process uncertainties," Fuzzy Sets and Systems, vol. 160, no. 18, pp. 2640-2657, 2009.

[12] M. D. A. Serna, C. A. Serna, and G. P. Ortega, "Parametric linear programming for a materials requirement planning problem 
solution with uncertainty," Ingenieria e Investigacion, vol. 30, no. 3, pp. 96-105, 2010.

[13] P. J. Billington, J. O. McClain, and L. J. Thomas, "Mathematical programming approaches to capacity-constrained MRP systems: review, formulation and problem reduction," Management Science, vol. 29, no. 10, pp. 1126-1141, 1983.

[14] M. L. Junior and M. G. Filho, "Production planning and control for remanufacturing: literature review and analysis," Production Planning \& Control, vol. 23, no. 6, pp. 419-435, 2012.

[15] S. D. Morgan and R. J. Gagnon, "A systematic literature review of remanufacturing scheduling," International Journal of Production Research, vol. 51, no. 16, pp. 4853-4879, 2013.

[16] M. Omar and I. Yeo, "A production-repair inventory model with time-varying demand and multiple setups," International Journal of Production Economics, vol. 155, pp. 398-405, 2014.

[17] T. Li, P. Lin, G.-J. Sun, and H.-H. Liu, "Application of fuzzy programming with recourse in material requirement planning problem," in Proceedings of the International Conference on Measuring Technology and Mechatronics Automation (ICMTMA '09), vol. 2, pp. 546-549, Zhangjiajie, China, April 2009.

[18] E. Kim, S. Saghafian, and M. P. Van Oyen, "Joint control of production, remanufacturing, and disposal activities in a hybrid manufacturing-remanufacturing system," European Journal of Operational Research, vol. 231, no. 2, pp. 337-348, 2013.

[19] G. W. DePuy, J. S. Usher, R. L. Walker, and G. D. Taylor, "Production planning for remanufactured products," Production Planning and Control, vol. 18, no. 7, pp. 573-583, 2007.

[20] A. Corominas, A. Lusa, and J. Olivella, "A manufacturing and remanufacturing aggregate planning model considering a non-linear supply function of recovered products," Production Planning and Control, vol. 23, no. 2-3, pp. 194-204, 2012.

[21] C. Wei, Y. Li, and X. Cai, "Robust optimal policies of production and inventory with uncertain returns and demand," International Journal of Production Economics, vol. 134, no. 2, pp. 357367, 2011.

[22] V. D. R. Guide Jr., R. Srivastava, and M. E. Kraus, "Product structure complexity and scheduling of operations in recoverable manufacturing," International Journal of Production Research, vol. 35, no. 11, pp. 3179-3200, 1997.

[23] S. A. Melnyk, R. P. Sroufe, F. L. Montabon, and T. J. Hinds, "Green MRP: identifying the material and environmental impacts of production schedules," International Journal of Production Research, vol. 39, no. 8, pp. 1559-1573, 2001.

[24] S. M. Mirzapour Al-e-hashem, A. Baboli, and Z. Sazvar, "A stochastic aggregate production planning model in a green supply chain: considering flexible lead times, nonlinear purchase and shortage cost functions," European Journal of Operational Research, vol. 230, no. 1, pp. 26-41, 2013.

[25] Y. Barba-Gutiérrez, B. Adenso-Díaz, and S. M. Gupta, "Lot sizing in reverse MRP for scheduling disassembly," International Journal of Production Economics, vol. 111, no. 2, pp. 741-751, 2008.

[26] G. A. Süer, F. Arikan, and C. Babayiǧit, "Effects of different fuzzy operators on fuzzy bi-objective cell loading problem in labor-intensive manufacturing cells," Computers and Industrial Engineering, vol. 56, no. 2, pp. 476-488, 2009.

[27] F. David, H. Pierreval, and C. Caux, "Enterprise resource planning systems in the aluminium conversion industry," Production Planning and Control, vol. 16, no. 8, pp. 785-795, 2005.

[28] K. Inderfurth, S. D. P. Flapper, A. J. D. Lambert, C. P. Pappis, and T. G. Voutsinas, "Production planning for product recovery management," in Reverse Logistics: Quantitative Models for Closed-Loop Supply Chains, pp. 249-274, Springer, Berlin, Germany, 2004.

[29] Y. He, "Acquisition pricing and remanufacturing decisions in a closed-loop supply chain," International Journal of Production Economics, vol. 163, pp. 48-60, 2015.

[30] L. A. Zadeh, "Fuzzy sets as a basis for a theory of possibility," Fuzzy Sets and Systems, vol. 1, no. 1, pp. 3-28, 1978.

[31] A. L. Guiffrida and R. Nagi, "Fuzzy set theory applications in production management research: a literature survey," Journal of Intelligent Manufacturing, vol. 9, no. 1, pp. 39-56, 1998.

[32] A. Dolgui and C. Prodhon, "Supply planning under uncertainties in MRP environments: a state of the art," Annual Reviews in Control, vol. 31, no. 2, pp. 269-279, 2007.

[33] B. Grabot, L. Geneste, G. Reynoso-Castillo, and S. Vérot, "Integration of uncertain and imprecise orders in the MRP method," Journal of Intelligent Manufacturing, vol. 16, no. 2, pp. 215-234, 2005.

[34] J. C. Figueroa-García, D. Kalenatic, and C. A. Lopez-Bello, "Multi-period mixed production planning with uncertain demands: fuzzy and interval fuzzy sets approach," Fuzzy Sets and Systems, vol. 206, pp. 21-38, 2012.

[35] B. Bilgen, "Application of fuzzy mathematical programming approach to the production allocation and distribution supply chain network problem," Expert Systems with Applications, vol. 37, no. 6, pp. 4488-4495, 2010.

[36] S. Lu, H. Su, L. Xiao, and L. Zhu, "Application of two-phase fuzzy optimization approach to multiproduct multistage integrated production planning with linguistic preference under uncertainty," Mathematical Problems in Engineering, vol. 2015, Article ID 780830, 20 pages, 2015.

[37] M. S. Pishvaee and S. A. Torabi, "A possibilistic programming approach for closed-loop supply chain network design under uncertainty," Fuzzy Sets and Systems, vol. 161, no. 20, pp. 26682683, 2010.

[38] E. U. Olugu and K. Y. Wong, "An expert fuzzy rule-based system for closed-loop supply chain performance assessment in the automotive industry," Expert Systems with Applications, vol. 39, no. 1, pp. 375-384, 2012.

[39] M. A. Parra, A. B. Terol, B. P. Gladish, and M. V. R. Uría, “Solving a multiobjective possibilistic problem through compromise programming," European Journal of Operational Research, vol. 164, no. 3, pp. 748-759, 2005.

[40] Y.-F. Lan, Y.-K. Liu, and G.-J. Sun, "Modeling fuzzy multiperiod production planning and sourcing problem with credibility service levels," Journal of Computational and Applied Mathematics, vol. 231, no. 1, pp. 208-221, 2009.

[41] A. K. Srivastava and A. K. Nema, "Fuzzy parametric programming model for multi-objective integrated solid waste management under uncertainty," Expert Systems with Applications, vol. 39, no. 5, pp. 4657-4678, 2012.

[42] X. Zhang, F. Zhang, X. Chen, and Z. Wan, "Polymorphic uncertain linear programming for generalized production planning problems," Journal of Optimization, vol. 2014, Article ID 896756, 10 pages, 2014.

[43] S.-P. Chen and W.-L. Huang, "Solving fuzzy multiproduct aggregate production planning problems based on extension principle," International Journal of Mathematics and Mathematical Sciences, vol. 2014, Article ID 207839, 18 pages, 2014.

[44] N. Madadi and K. Y. Wong, "A multiobjective fuzzy aggregate production planning model considering real capacity and quality of products," Mathematical Problems in Engineering, vol. 2014, Article ID 313829, 15 pages, 2014. 
[45] S. A. Torabi, M. Ebadian, and R. Tanha, "Fuzzy hierarchical production planning (with a case study)," Fuzzy Sets and Systems, vol. 161, no. 11, pp. 1511-1529, 2010.

[46] P. Kundu, S. Kar, and M. Maiti, "Fixed charge transportation problem with type-2 fuzzy variables," Information Sciences, vol. 255, pp. 170-186, 2014.

[47] A. Srinivasan and G. Geetharamani, "Linear programming problem with interval type 2 fuzzy coefficients and an interpretation for ITS constraints," Journal of Applied Mathematics, vol. 2016, Article ID 8496812, 11 pages, 2016.

[48] R. R. Yager, "A procedure for ordering fuzzy subsets of the unit interval," Information Sciences, vol. 24, no. 2, pp. 143-161, 1981.

[49] G. J. Klir and B. Yuan, Fuzzy Sets and Fuzzy Logic: Theory and Applications, Prentice Hal-PTR, Upper Saddle River, NJ, USA, 1995.

[50] J. Kacprzyk and S. A. Orlovski, Eds., Optimization Models Using Fuzzy Sets and Possibility Theory, 1987.

[51] H. Tanaka, T. Okuda, and K. Asai, "On fuzzy-mathematical programming," Journal of Cybernetics, vol. 3, no. 4, pp. 37-46, 1973.

[52] T.-F. Liang, "Fuzzy multi-objective production/distribution planning decisions with multi-product and multi-time period in a supply chain," Computers and Industrial Engineering, vol. 55, no. 3, pp. 676-694, 2008.

[53] T.-F. Liang and H.-W. Cheng, "Application of fuzzy sets to manufacturing/distribution planning decisions with multi-product and multi-time period in supply chains," Expert Systems with Applications, vol. 36, no. 2, pp. 3367-3377, 2009.

[54] R. C. Wang and T. F. Liang, "Applying possibilistic linear programming to aggregate production planning," International Journal of Production Economics, vol. 98, no. 3, pp. 328-341, 2005.

[55] M. Jiménez, M. Arenas, A. Bilbao, and M. V. Rodríguez, "Linear programming with fuzzy parameters: an interactive method resolution," European Journal of Operational Research, vol. 177, no. 3, pp. 1599-1609, 2007.

[56] M. Gen, Y. Tsujimura, and K. Ida, "Method for solving multiobjective aggregate production planning problem with fuzzy parameters," Computers and Industrial Engineering, vol. 23, no. 1-4, pp. 117-120, 1992.

[57] L. A. Zadeh, "The concept of a linguistic variable and its application to approximate reasoning-II," Information Sciences, vol. 8, pp. 301-357, 1975.

[58] L. A. Zadeh, "The concept of a linguistic variable and its application to approximate reasoning-I," Information Sciences, vol. 8, no. 3, pp. 199-249, 1975.

[59] AIMMS 4.1 x64 AIMMS B.V., Haarlem, The Netherlands, 2014, http://www.aimms.com/. 


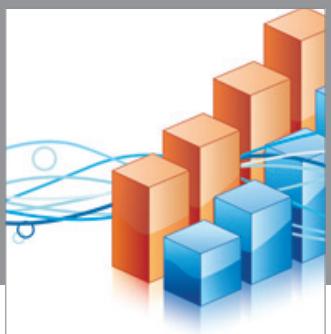

Advances in

Operations Research

vatem alat4

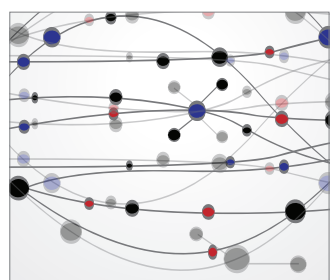

\section{The Scientific} World Journal
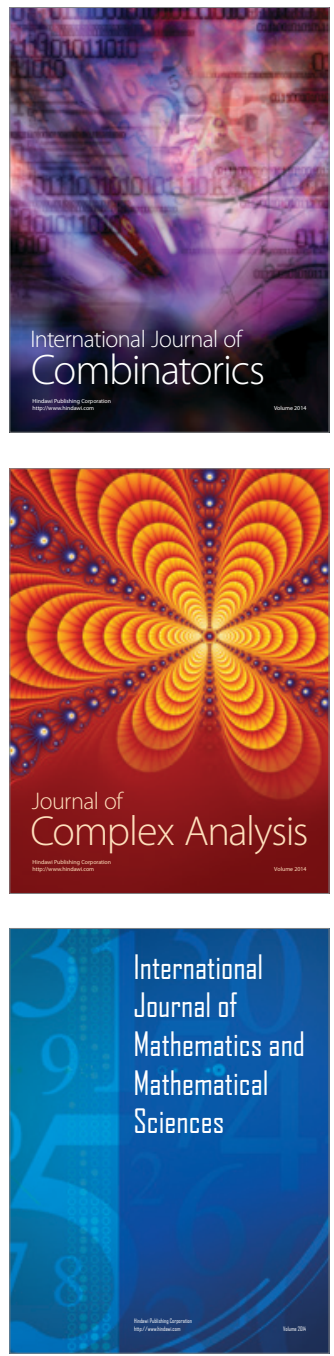
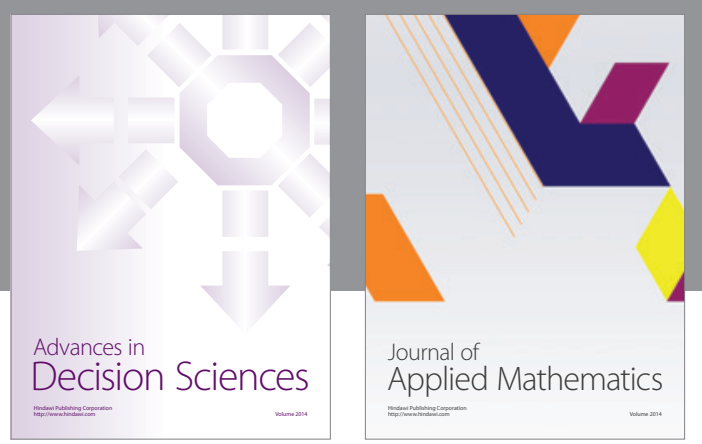

Algebra

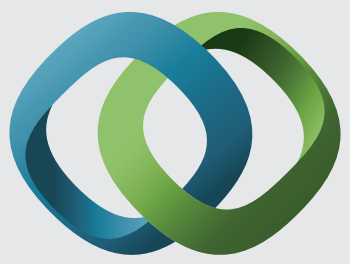

\section{Hindawi}

Submit your manuscripts at

http://www.hindawi.com
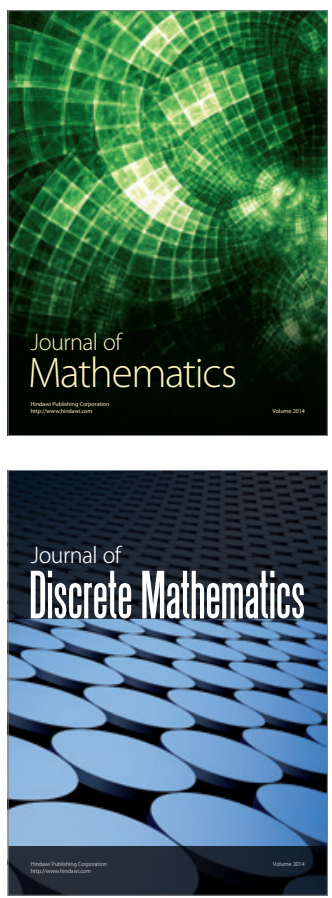

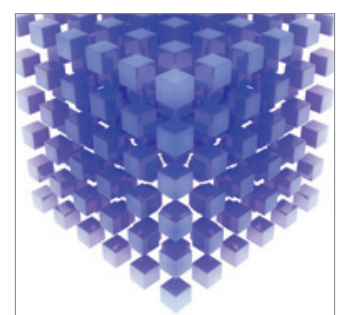

Mathematical Problems in Engineering
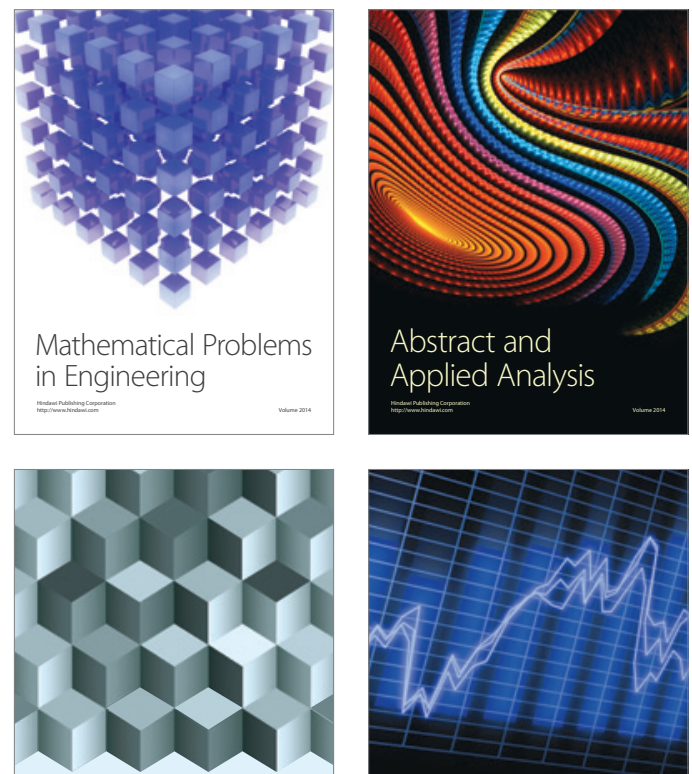

Journal of

Function Spaces

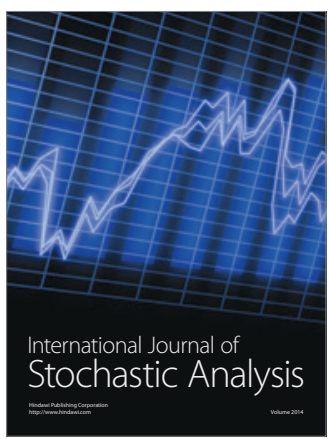

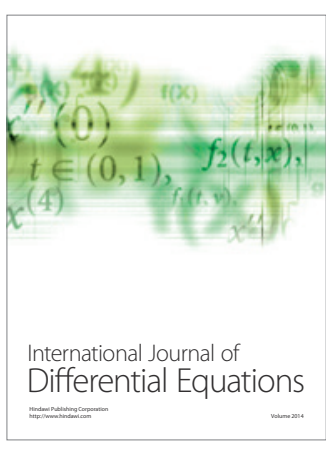
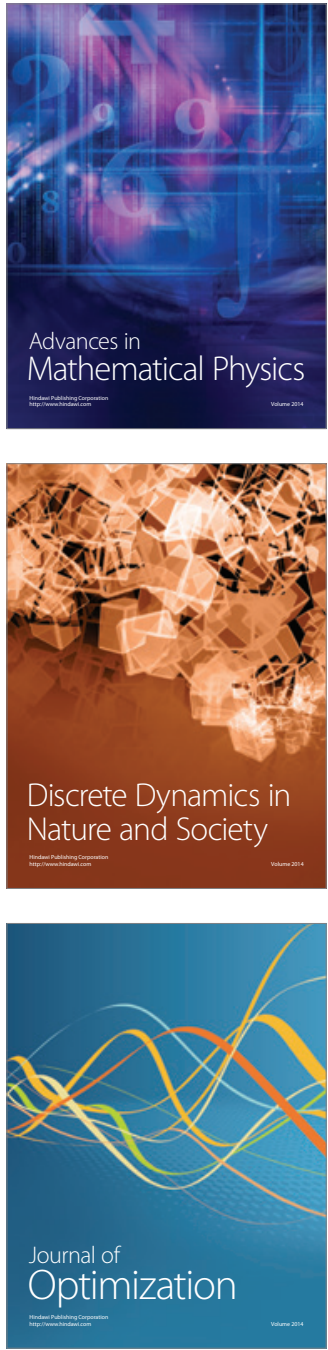